\title{
A Novel Long-Noncoding RNA LncZFAS1 Prevents MPP+-Induced Neuroinflammation Through MIB1 Activation
}

\author{
Ziman Zhu ${ }^{1} \cdot$ Peiling Huang ${ }^{2} \cdot$ Ruifeng Sun ${ }^{1} \cdot$ Xiaoling $\mathrm{Li}^{1} \cdot$ Wenshan $\mathrm{Li}^{1} \cdot$ Weijun Gong ${ }^{2}$ (C)
}

Received: 29 July 2021 / Accepted: 26 October 2021 / Published online: 13 November 2021

(c) The Author(s) 2021

\begin{abstract}
Parkinson's disease remains one of the leading neurodegenerative diseases in developed countries. Despite well-defined symptomology and pathology, the complexity of Parkinson's disease prevents a full understanding of its etiological mechanism. Mechanistically, $\alpha$-synuclein misfolding and aggregation appear to be central for disease progression, but mitochondrial dysfunction, dysfunctional protein clearance and ubiquitin/proteasome systems, and neuroinflammation have also been associated with Parkinson's disease. Particularly, neuroinflammation, which was initially thought to be a side effect of Parkinson's disease pathogenesis, has now been recognized as driver of Parkinson's disease exacerbation. Next-generation sequencing has been used to identify a plethora of long noncoding RNAs (lncRNA) with important transcriptional regulatory functions. Moreover, a myriad of lncRNAs are known to be regulators of inflammatory signaling and neurodegenerative diseases, including IL-1 $\beta$ secretion and Parkinson's disease. Here, LncZFAS1 was identified as a regulator of inflammasome activation, and pyroptosis in human neuroblast SH-SY5Y cells following MPP ${ }^{+}$treatment, a common in vitro Parkinson's disease cell model. Mechanistically, TXNIP ubiquitination through MIB1 E3 ubiquitin ligase regulates NLRP3 inflammasome activation in neuroblasts. In contrast, $\mathrm{MPP}^{+}$activates the NLPR3 inflammasome through miR590-3p upregulation and direct interference with MIB1-dependent TXNIP ubiquitination. LncZFAS overexpression inhibits this entire pathway through direct interference with miR590-3p, exposing a novel research idea regarding the mechanism of Parkinson's disease.
\end{abstract}

Keywords LncZFAS · Parkinson's disease · Pyroptosis · MIB1 · TXNIP · NLRP3

\section{Introduction}

Parkinson's disease is one of the leading neurodegenerative diseases in developed countries, affecting $1-2 \%$ of the elderly population (above 65 years old)[1]. The World Health Organization predicts that the incidence of Parkinson's disease will double by 2030[2], resulting in a significant loss of healthy life years. Parkinson's disease syndrome is defined by tremor, rigidity, progressive akinesia, and/or

Ziman Zhu and Peiling Huang contributed equally to this manuscript.

Weijun Gong

gwj197104@ccmu.edu.cn

1 Beijing Rehabilitation Medicine Academy, Capital Medical University, Beijing 100144, China

2 Department of Neurological Rehabilitation, Beijing Rehabilitation Hospital, Capital Medical University, Beijing 100144, China postural disturbance. Parkinson's disease is a multifactorial disease with both genetic and environmental factors, but the complete etiological scenario remains unknown. Nonetheless, Parkinson's disease pathology is well defined and is primarily characterized by the loss of dopaminergic neurons in the substantia nigra[3]. Mechanistically, $\alpha$-synuclein misfolding and aggregation appears to be central for disease progression, but mitochondrial dysfunction, dysfunctional protein clearance and ubiquitin/proteasome systems, and neuroinflammation have also been associated with Parkinson's disease.

Without a well-defined etiological model, the development and identification of novel therapeutic targets must rely on high throughput screening in immortalized or primary neural cell lines[4]. SH-SY5Y human neuroblasts are commonly used as an alternative to laborious and highly heterogeneous primary dopaminergic neuron cultures from rat/mouse embryos[5, 6]. Regardless of the cell model, 1-methyl-4-phenylpyridinium $\left(\mathrm{MPP}^{+}\right)$is used to induce Parkinson's disease-like cellular disease. $\mathrm{MPP}^{+}$is a 
dopaminergic neurotoxin and the active metabolite of MPT (1-methyl-4-phenyl-1,2,3,6-tetrahydropyridine), which is known to cause human parkinsonism after injection[7].

Neuroinflammation was initially thought to be a side effect of Parkinson's disease pathogenesis. However, this concept has now been revised, and microglial inflammatory signals are known to exacerbate and significantly contribute to Parkinson's disease progression[8-11]. Inflammasomes sense microbial infection or host-derived danger signals indicative of metabolic perturbations[12]. These large multimeric caspase-1-activating complexes control the maturation and secretion of interleukins, such as IL-1b and IL-18, with potent proinflammatory activities against infection and injury[12, 13]. Many inflammasomes are activated through direct interaction with pathogen- or dangerassociated molecular patterns (PAMPs and DAMPs, respectively)[12]. However, Nod-like receptor with pyrin domain (NLRP) 3 can sense intracellular metabolic perturbations, such as intracellular ATP and $\mathrm{K}^{+}$ion imbalance or oxidative stress, through as yet unclear mechanisms[14]. Perhaps, for this reason, NLRP3 has been extensively studied in autoimmune disease and chronic inflammation $[15,16]$. Furthermore, MPTP-driven NLRP3 inflammasome activation in microglia has recently been shown to play a central role in dopaminergic neurodegeneration and Parkinson's disease[17]. NLRP3 is regulated by both post-transcriptional and post-translational signals[18]. In homeostasis, NLRP3 is generally expressed at extremely low levels, but is quickly and highly upregulated after PAMP or DAMP prime signaling[19]. In the cytosol, NLRP3 senses $\mathrm{K}^{+}$efflux, intracellular oxidative stress, or extracellular elevated ATP levels[19]; any of these metabolic perturbations induce NLRP3 oligomerization, interaction with the adaptor protein ASC, and recruitment of cysteine protease pro-caspase-1[5]. Autocatalysis and activation of caspase-1 lead to cleavage, maturation, and secretion of proinflammatory cytokines, including IL- $1 \beta$ and IL-18, and, sometimes, induce programmed inflammatory cell death by pyroptosis[20-23]. NLRP3 activation promotes the secretion of the inflammatory cytokine interleukin-1 $\beta / 18$ (IL-1 $\beta / 18$ ) and induces pyroptosis to rupture microglia to further release inflammatory factor in Parkinson's disease[24].

The next-generation sequencing revolution identified a plethora of long noncoding RNAs (lncRNAs), which were previously assumed to be biologically irrelevant, but are now known to have important transcriptional regulatory functions[25]. Recently, lncRNAs have also been shown to regulate protein expression post-transcriptionally through interference with microRNAs (miRs), smaller noncoding RNAs that directly bind to protein-coding mRNA, inhibiting translation and promoting transcript degradation[26, 27]. Moreover, a myriad of lncRNAs and miRs have been linked to the regulation of inflammatory signaling and neurodegenerative diseases, including IL- $1 \beta$ secretion and Parkinson's disease[28, 29].

ZNFX1 antisense RNA 1 (ZFAS1) was recently identified as a novel lncRNA transcribed from the antisense orientation of zinc finger NFX1-type containing 1 (ZNFX1) located on chromosome 20q13.13[30]. Over the past 5 years, LncZFAS1 has emerged as a regulatory factor in multiple diseases, including acute myocardial infarction[31, 32], rheumatoid arthritis[33], and cancer[34]. Interestingly, much like Parkinson's disease, myocardial infarction and rheumatoid arthritis are also driven and exacerbated by dysregulated inflammasome activation[35]. Furthermore, LncZFAS1 shows a broad molecular functional profile interfering in complex pathways including cell proliferation and cell death[36]. Therefore, we hypothesized that LncZFAS 1 might regulate inflammasome activation and pyroptosis during Parkinson's disease. Here, LncZFAS1 was identified as a regulator of inflammasome activation and pyroptosis in human neuroblast SH-SY5Y cells following $\mathrm{MPP}^{+}$treatment. This work unveils a potential beneficial role of LncZFAS1 during Parkinson's disease progression, which could be explored as a new research idea to elucidate the mechanism of Parkinson's disease.

\section{Materials and Methods}

\section{Tissue Culture}

SH-SY5Y cells were acquired from ATCC and maintained in Dulbecco-modified Eagle medium (DMEM)/F12 (1:1) with penicillin $(100 \mathrm{U} / \mathrm{mL})$, streptomycin $(100 \mu \mathrm{g} / \mathrm{mL})$, and $10 \%$ fetal bovine serum (FBS). At 90\% confluency, the monolayer was washed twice with phosphate buffered saline (PBS), and the cells were chemically detached with $0.05 \%$ trypsin for $2 \mathrm{~min}$. After quenching with complete media, the cells were pelleted by centrifugation at $800 \mathrm{rpm}$ for $5 \mathrm{~min}$, washed twice with PBS, resuspended in complete medium and $3 \times$ $10^{4}$ to $10^{6}$ cells seeded in $10-\mathrm{cm}$ tissue culture dishes. The medium was changed every other day. SH-SY5Y cells were differentiated into dopaminergic neuron-like cells with (10 $\mu \mathrm{M})$ retinoic acid in DMEM (1\%FBS) for 5 days. On differentiation, cell adherence was confirmed under the microscope, and the remaining suspension cells were removed by gentle washing.

\section{Pyroptosis Assay}

SH-SY5Y cells were seeded in 6-well plates at $10^{6}$ cells/ well for $24 \mathrm{~h}$ and then treated with increasing $\mathrm{MPP}^{+}$concentrations for $24 \mathrm{~h}$. Cells were gently washed with PBS and chemically detached with $0.05 \%$ trypsin/EDTA. After detachment, trypsin was quenched with complete media, 
cells were pelleted by centrifugation, and the caspase activity was detected with the FAM-FLICA caspase-1 assay kit (ImmunoChemistry Technologies, LLC, Bloomington, MN, USA) according to the manufacturer's recommendations. Briefly, cells were stained and incubated with FLICA (1:30) for $1 \mathrm{~h}$ at $37^{\circ} \mathrm{C}$ protected from light. Cells were then by washed with 5 volumes of $1 \times$ wash buffer, pelleted by centrifugation, resuspended in $1 \times$ apoptosis wash buffer with 5 $\mu \mathrm{L}$ of propidium iodide (PI), and incubated for $10 \mathrm{~min}$ at 37 ${ }^{\circ} \mathrm{C}$ protected from light. Data were acquired with a Beckman DxFlex flow cytometer (Beckman, Brea, CA, USA) and analyzed with CytExpert (Beckman Coulter Inc, CA, USA). Single stain controls were used to calculate the "compensation," which refers to the process of correcting fluorescence spillover, that is, removing the signal of any given fluorochrome from all detectors except the one devoted to measuring that dye. PI-positive cells were detected according to the operating procedure of PI-staining kit (KeyGEN Biotech, Nanjing, China)

\section{Total Protein Extraction}

Cells were seeded in 6-well plates at $10^{6}$ cells/well and treated with $1 \mathrm{mM} \mathrm{MPP}{ }^{+}$. When designated, cells were also treated with miRr590-3p mimic or inhibitor and corresponding negative controls. At designated timepoints, cells were washed with pre-cooled PBS and lysed with $1 \mathrm{~mL}$ of RIPA buffer supplemented with phenylmethyl sulfonyl fluoride (PMSF) for each $100 \mu \mathrm{L}$ of sample. After full lysis, samples were centrifuged at $12,000 \mathrm{~g}, 4^{\circ} \mathrm{C}$, for $5 \mathrm{~min}$, the supernatant was immediately transferred to a clean pre-cooled tube and stored at $-80{ }^{\circ} \mathrm{C}$ for later analysis. The total protein content was quantified by BCA method, in which $25 \mu$ g protein was added to $5 \times$ loading buffer and boiled for $10 \mathrm{~min}$ in a water bath for denaturing. Samples were stored at $-20{ }^{\circ} \mathrm{C}$ until required for western blotting.

\section{Co-Immunoprecipitation (Co-IP) Assay}

Protein extracts were prepared as described above. Protein A/G-agarose microspheres were washed twice with PBS and adjusted to a $50 \%$ agarose microsphere concentration in PBS. In detail, $100 \mu \mathrm{L}$ of $50 \%$ of protein A/G-agarose microspheres was added to $1 \mathrm{~mL}$ of sample and incubated in a horizontal shaker at $4{ }^{\circ} \mathrm{C}$ for $10 \mathrm{~min}$ to remove unspecific binding. Samples were then centrifuged at $14,000 \mathrm{~g}$ for 15 min at $4{ }^{\circ} \mathrm{C}$, and the supernatant was transferred to a clean centrifuge tube. Total protein was estimated by the BCA method and adjusted to $3 \mu \mathrm{g} / \mu \mathrm{L}$ with PBS. Immunoprecipitation microspheres were prepared in $500 \mu \mathrm{L}$ with pre-titrated target antibody and 1 volume of bead mixed with 7 volumes of sample. Samples were incubated overnight at 4 ${ }^{\circ} \mathrm{C}$ with gentle shaking, followed by centrifugation at 14,000 $\mathrm{g}$ for $5 \mathrm{~s}$. The precipitate was collected and washed three times with pre-cooled washing buffer $(800 \mu \mathrm{L}$ per wash). The pellet was resuspended in a suitable volume of loading buffer, and the supernatant was collected for further downstream SDS-PAGE western-blot analysis.

\section{Western Blotting}

Denatured samples were loaded in $10 \%$ or $12 \%$ resolving and $5 \%$ stacking SDS-PAGE gels prepared in house. The samples were separated by electrophoresis in the MINI-PTET (BioRad, CA, USA) system at $120 \mathrm{~V}$ for 5 min (stacking) and $80 \mathrm{~V}$ (resolving) for approximately $30 \mathrm{~min}$ with prechilled $1 \times$ electrophoresis buffer. Five microliters of 3 -color pre-stained protein ladder (Green, BioReseach LLC, LA, USA) was used as the standard for protein size estimation. For transfer, the PVDF membrane was pre-activated in methanol for $1 \mathrm{~min}$ and then immersed in the transfer buffer for $15 \mathrm{~min}$. The samples were transferred with a semi-dry blot apparatus (BioRad, California, USA). The transfer efficiency was confirmed by Ponceau $\mathrm{S}$ staining. For specific protein expression, the membranes were incubated with primary antibody, at pre-titrated concentrations (Table 1) in Tris-buffered saline/0.05\% Tween 20 (TBST) and self-sealing bags, followed by incubation overnight at $4{ }^{\circ} \mathrm{C}$. The membranes were then washed three times with TBST for 10 min with gentle rocking, and antibody binding was detected with appropriate HRP-conjugated secondary antibody at pre-titrated concentrations in ziplock bags for 1 $\mathrm{h}$ at room temperature. The membranes were washed a further three times with TBST. The membranes were developed with enhanced chemiluminescence (ECL) solution (Thermo Fisher Scientific, Pittsburgh, PA, USA) for $5 \mathrm{~min}$, according to the manufacturer's instructions. Membranes were imaged with Tanon 6600 Luminescent Imaging Workstation (Tanon, Shanghai, China), and the relative protein expression levels were quantified with Image Pro Plus 6.0 software (Media Cybernetics, Rockville, MD, USA). The expression level

Table 1 Antibodies and dilution

\begin{tabular}{lll}
\hline Antibodies & Dilution (application) & Source and Cat\# \\
\hline NLRP3 & $1: 1000(\mathrm{WB})$ & Abcam-ab214185 \\
Gsdmd & $1: 1000(\mathrm{WB})$ & Abcam-ab210070 \\
ASC & $1: 100(\mathrm{IP})$ & Abcam-ab151700 \\
TXNIP & $1: 1000(\mathrm{WB}), 1: 200(\mathrm{IP})$ & Abcam-ab188865 \\
TRX1 & $1: 100(\mathrm{IP})$ & Abcam-ab26320 \\
MIB1 & $1: 1000(\mathrm{WB})$ & Abcam-ab124929 \\
IL1 $\beta$ & $1: 1000(\mathrm{WB})$ & Abcam-ab229696 \\
Ubiquitin & $1: 2000(\mathrm{WB})$ & Abcam-ab7780 \\
Caspase-1 & $1: 1000(\mathrm{WB})$ & CST-89332 \\
GAPDH & $1: 10,000(\mathrm{WB})$ & Abcam-ab181602 \\
\hline
\end{tabular}


was calculated as [target protein gray value]/[internal reference protein gray value].

\section{RNA Extraction}

SH-SY5Y cells were treated with $\mathrm{MPP}^{+}$as described above. At $90 \%$ confluency or designated timepoints, the cells were chemically detached with trypsin and lysed with RNAiso plus Trizol at room temperature for $10 \mathrm{~min}$, before the RNA was extracted according to the manufacturer's recommendations. Briefly, 1/5 volume of chloroform was added, samples were shaken and let stand at room temperature for $5 \mathrm{~min}$, followed by $15 \mathrm{~min}$ centrifugation at $12,000 \mathrm{~g}, 4{ }^{\circ} \mathrm{C}$. The supernatants were transferred to a centrifuge tube, 1 volume of isopropanol was added, and the samples were inverted and mixed vigorously. After 10-min incubation on ice, the samples were centrifuged at $12,000 \mathrm{~g}, 4^{\circ} \mathrm{C}$, for $10 \mathrm{~min}$, and the supernatant was discarded. The RNA was washed with $1 \mathrm{~mL}$ of $75 \%$ ethanol, air-dried (5-10 $\mathrm{min}$ ), and resuspended in $20 \mu \mathrm{L}$ of RNase-free water. The RNA content, purity, and quality were estimated with Nanodrop 2000 (Thermo Fisher, Pittsburgh, PA, USA) ( $2 \mu \mathrm{L}$ of sample).

\section{MicroRNA Extraction}

MiRNA was extracted with a tissue/cell miRNA extraction kit (Haigene, Harbin, China) according to the manufacturer's recommendations. In brief, $300 \mu \mathrm{L}$ of miRNA Reagent $\mathrm{A}$ was added, and the sample was mixed by inversion and incubated at room temperature for $5 \mathrm{~min}$. After lysis, $250 \mu \mathrm{L}$ of miRNA ReagentB was added, again mixed by inversion and centrifuged at 13,000 rpm for $5 \mathrm{~min}$. The supernatant was transferred to a clean $1.5-\mathrm{mL}$ tube, $200 \mu \mathrm{L}$ of absolute ethanol was added and mixed vigorously, and the sample was incubated at room temperature for $5 \mathrm{~min}$ with shaking. After centrifugation at 13,000 rpm for $10 \mathrm{~min}$, isopropanol was added (3:7 volume ratio), and the sample was inverted several times and loaded into the miRNA adsorption column. The column was washed twice with $75 \%$ absolute ethanol, dried for $10 \mathrm{~min}$, and eluted with $30 \mu \mathrm{L}$ RnaseFree TE buffer to a new tube by centrifugation at $13,000 \mathrm{rpm}$ for $2 \mathrm{~min}$.

\section{Quantitative Real-Time Polymerase Chain Reaction (qRT-PCR)}

First-strand cDNA reverse transcription from mRNA was performed using the iScript cDNA Synthesis Kit (BioRad, Hercules, CA, USA) in $20-\mu \mathrm{L}$ reactions with $2 \mu \mathrm{L}$ of total RNA, according to the manufacturer's recommendations. The reaction was performed at $25{ }^{\circ} \mathrm{C}$ for $5 \mathrm{~min}, 42^{\circ} \mathrm{C}$ for $30 \mathrm{~min}$, and $85^{\circ} \mathrm{C}$ for $5 \mathrm{~min}$, and cDNA was stored at -70 ${ }^{\circ} \mathrm{C}$. qRT-PCR was performed using the Sofast EvaGreen Supermix system (BioRad, Hercules, CA, USA) in $20-\mu \mathrm{L}$
Table 2 qRT-PCR protocol

\begin{tabular}{ll}
\hline Step1: $95{ }^{\circ} \mathrm{C}$ & $15 \mathrm{~min}$ \\
\hline Step2: $95{ }^{\circ} \mathrm{C}$ & $5 \mathrm{~s}$ \\
$55{ }^{\circ} \mathrm{C}$ & $5 \mathrm{~s}$ \\
$70{ }^{\circ} \mathrm{C}$ & $30 \mathrm{~s}$ \\
Step2: $30-40$ cycles & \\
Step3: $4{ }^{\circ} \mathrm{C}$ & $\begin{array}{c}\text { Disso- } \\
\text { ciation } \\
\end{array}$ \\
& analysis \\
\hline
\end{tabular}

Table 3 Primers used in quantitative real-time PCR

\begin{tabular}{|c|c|c|}
\hline Gene target & Primers & Sequence $5^{\prime}-3^{\prime}$ \\
\hline \multirow[t]{2}{*}{ LncRNAZFAS1 } & Forward & 5'-AACCAGGCTTTGATTGAACC-3' \\
\hline & Reverse & 5'-ATTCCATCGCCAGTTTCT-3' \\
\hline \multirow[t]{2}{*}{ TXNIP } & Forward & 5'-CAACTTGCTGCCCGACAAAA-3' \\
\hline & Reverse & 5'-TGGGTGGCATGCAAGGTATT-3' \\
\hline \multirow[t]{2}{*}{ MIB1 } & Forward & $\begin{array}{l}\text { 5'-TGGGGATTCATTGCTGCT } \\
\text { AGAT-3' }\end{array}$ \\
\hline & Reverse & $\begin{array}{l}\text { 5'-ACAGTGTAAGAGGGCTAG } \\
\text { AGAC-3 }\end{array}$ \\
\hline \multirow[t]{2}{*}{ GAPDH } & Forward & 5'-GGTCTCCTCTGACTTCAACA-3' \\
\hline & Reverse & 5'-GTGAGGGTCTCTCTCTTCCT-3' \\
\hline \multirow[t]{2}{*}{ Hsa-miR-590-3p } & Forward & $\begin{array}{l}\text { 5'-AAAGATTCCAAGAAGCTAAGG } \\
\text { GTG-3' }\end{array}$ \\
\hline & Reverse & $\begin{array}{l}\text { 5'-CCTAACTGGTTTCCTGTG } \\
\text { CCTA-3' }\end{array}$ \\
\hline \multirow[t]{2}{*}{ U6 } & Forward & 5'-CTCGCTTCGGCAGCACA-3' \\
\hline & Reverse & 5'-AACGCTTCACGAATTTGCGT-3' \\
\hline
\end{tabular}

reactions with a $1-\mu \mathrm{L}$ cDNA template according to the manufacturer's recommendations in an ABI 7500 real-time quantitative PCR instrument (American Applied Biosystems, USA). First-strand cDNA reverse transcription from miR and lncRNA was performed using the one-step miR RT kit (Takara, Japan) in $20-\mu \mathrm{L}$ reactions with $4 \mu \mathrm{L}$ of RNA template according to the manufacturer's recommendations. The reaction was performed for $60 \mathrm{~min}$ at $37^{\circ} \mathrm{C}$, followed by 5 min at $95^{\circ} \mathrm{C}$. qRT-PCR was performed using the cDNA SYBR Green miRNA fluorescence quantitative PCR kit (Haigene, Harbin, China) in $20-\mu \mathrm{L}$ reactions with $2.5 \mu \mathrm{L}$ template cDNA. qRT-PCR was run in an ABI 7500 real-time quantitative PCR instrument (American Applied Biosystems, Foster, CA, USA). qRT-PCR protocols are shown in Table 2. Gene-target specific primers are shown in Table 3. Fold change differences in gene expression were calculated using the $2^{-\Delta \Delta} \mathrm{Ct}$ method.

\section{Lentiviral Production}

RNAi sequences were cloned into the GV493 plasmid and expanded in Escherichia coli DH5 $\alpha$ cells in house (Fig. S1). 


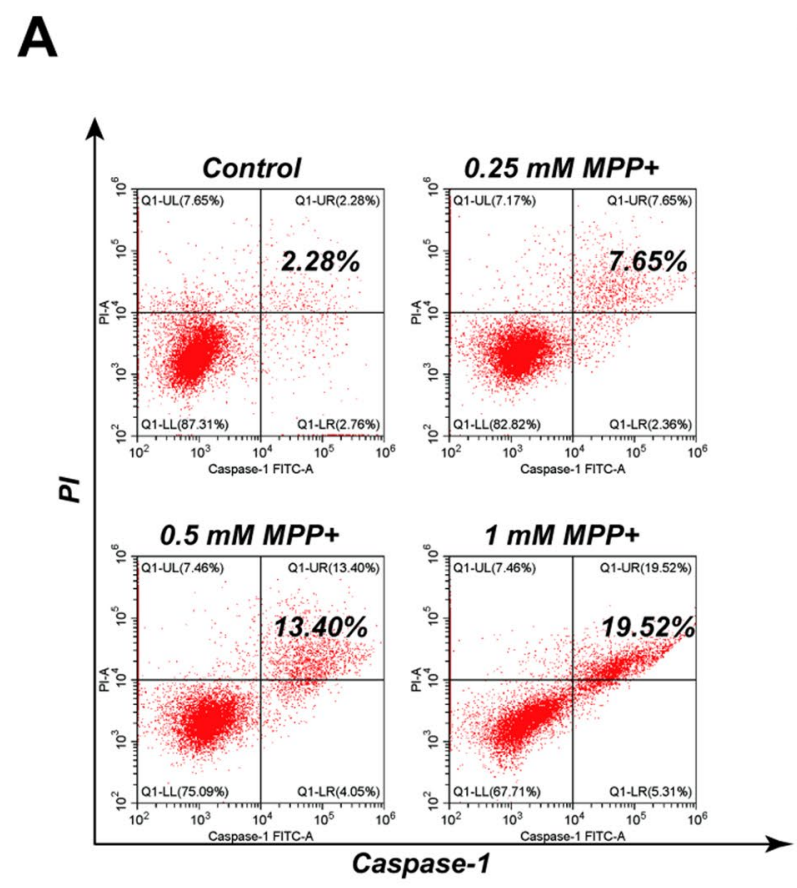

C

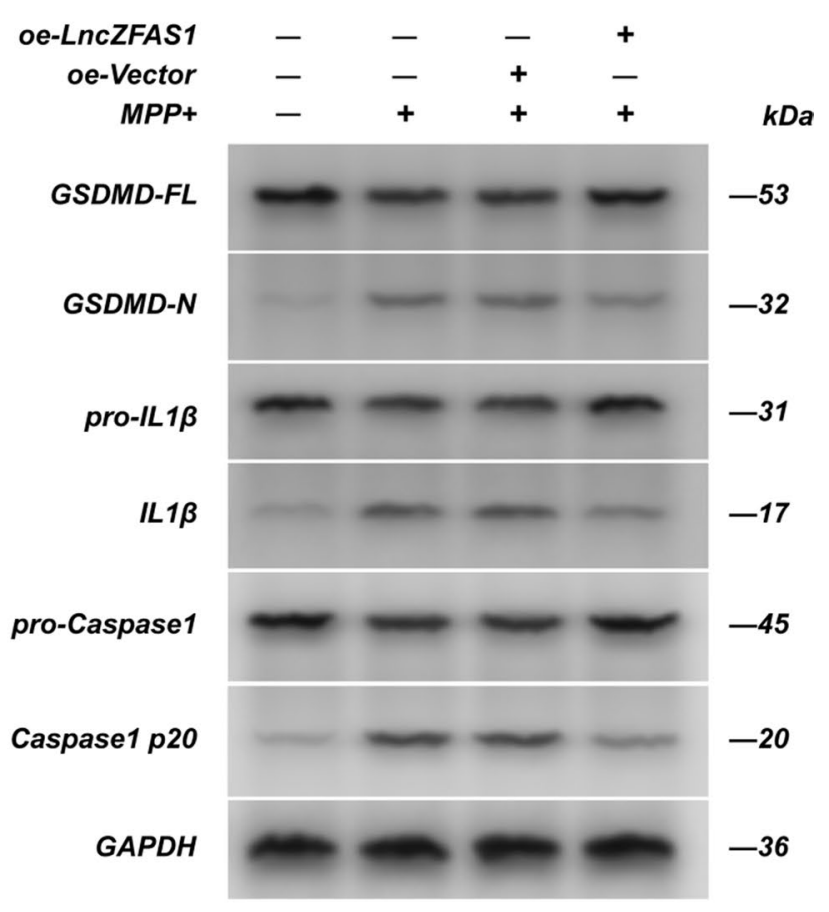

B

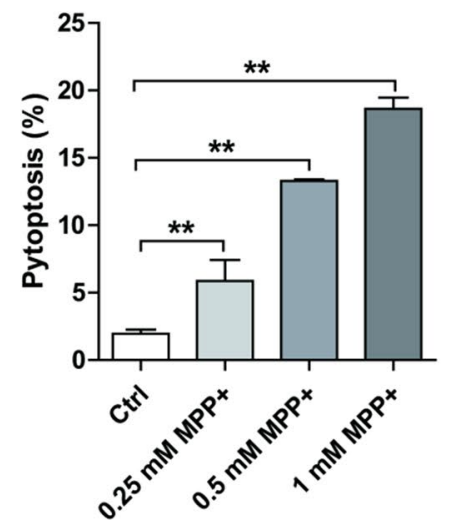

D
oe-LncZFAS
oe-Vecto
MPP
IP:ASC

Input

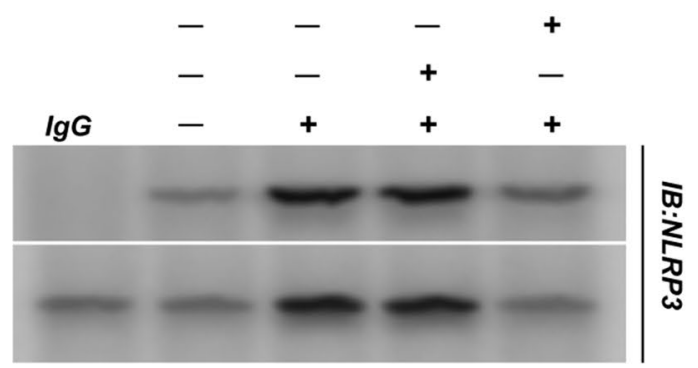

Fig. $1 \mathrm{MPP}^{+}$induced SH-SY5Y cell pyroptosis by inflammasome activation. SH-SY5Y cells were treated with $\mathrm{MPP}^{+}(0.25,0.5,1 \mathrm{mM})$ for $24 \mathrm{~h}$ and frequency of pyroptotic cells measure by flow cytometry. Frequency of pyroptotic cells was quantified by calculation of the internalization of PI and caspase-1 activation in the cells (A). Summary data for the frequency pyroptotic SH-SY5Y cells in the indicated groups as in $\mathbf{A}$. The frequency of pyroptotic cells was increased along with the concentration of $\mathrm{MPP}^{+}(\mathbf{B})$. Expression of inflammasome effector proteins Gsdmd-full length, Gsdmd-N, pro-IL1 $\beta$, IL-1 $\beta$,

The LncZFAS1 RNA sequence was cloned into pcDNA3.1 (Fig. S2). Lentiviral packaging was performed in $293 \mathrm{~T}$ cells seeded at $5 \times 10^{6}$ cells $/ 15 \mathrm{~mL}$ in T75 flasks in DMEM with $10 \%$ FBS for $24 \mathrm{~h}$ before transfection. At $70-80 \%$ confluency, cells were washed with PBS, 1 volume of serum-free medium was added, and the cells were incubated for $2 \mathrm{~h}$ at $37{ }^{\circ} \mathrm{C} 5 \% \mathrm{CO}_{2}$. The transfection mixture was prepared with $20 \mu \mathrm{L}$ of vector plasmid, mixed with $15 \mu \mathrm{L}$ pHelper1.0 pro-caspase-1, caspase-1 p20 in SH-SY5Y cells from the indicated group was detected by western blot assay. $\mathrm{MPP}^{+}$treatment significantly induced cleavage of Gsdmd, pro-IL- $1 \beta$, and caspase- 1 and had no impact on the protein levels of Gsdmd, pro-IL-1 $\beta$, and caspase-1 pre-cleaved peptides (C). NLRP3/ASC interaction detected following immunoprecipitation with anti-ASC or control IgG antibody (D). Results represent mean \pm SD of three individual experiments for each condition, performed in triplicate. ${ }^{*} p<0.05$, ${ }^{*} p<0.01$

vector plasmid, $10 \mu \mathrm{L}$ pHelper 2.0 vector plasmid, and GK transfection reagent (Genechem, Shanghai, China), in a 1 $\mathrm{mL}$ total reaction volume, and incubated at room temperature for $15 \mathrm{~min}$. The transfection mixture was slowly added to the 293T cell culture (in serum-free medium) with gentle rocking and incubated at $37{ }^{\circ} \mathrm{C}, 5 \% \mathrm{CO}_{2}$ for $6 \mathrm{~h}$. The cells were gently washed with warm PBS, and $20 \mathrm{~mL}$ of complete medium (with 10\% FBS) was added and incubated at 37 
A
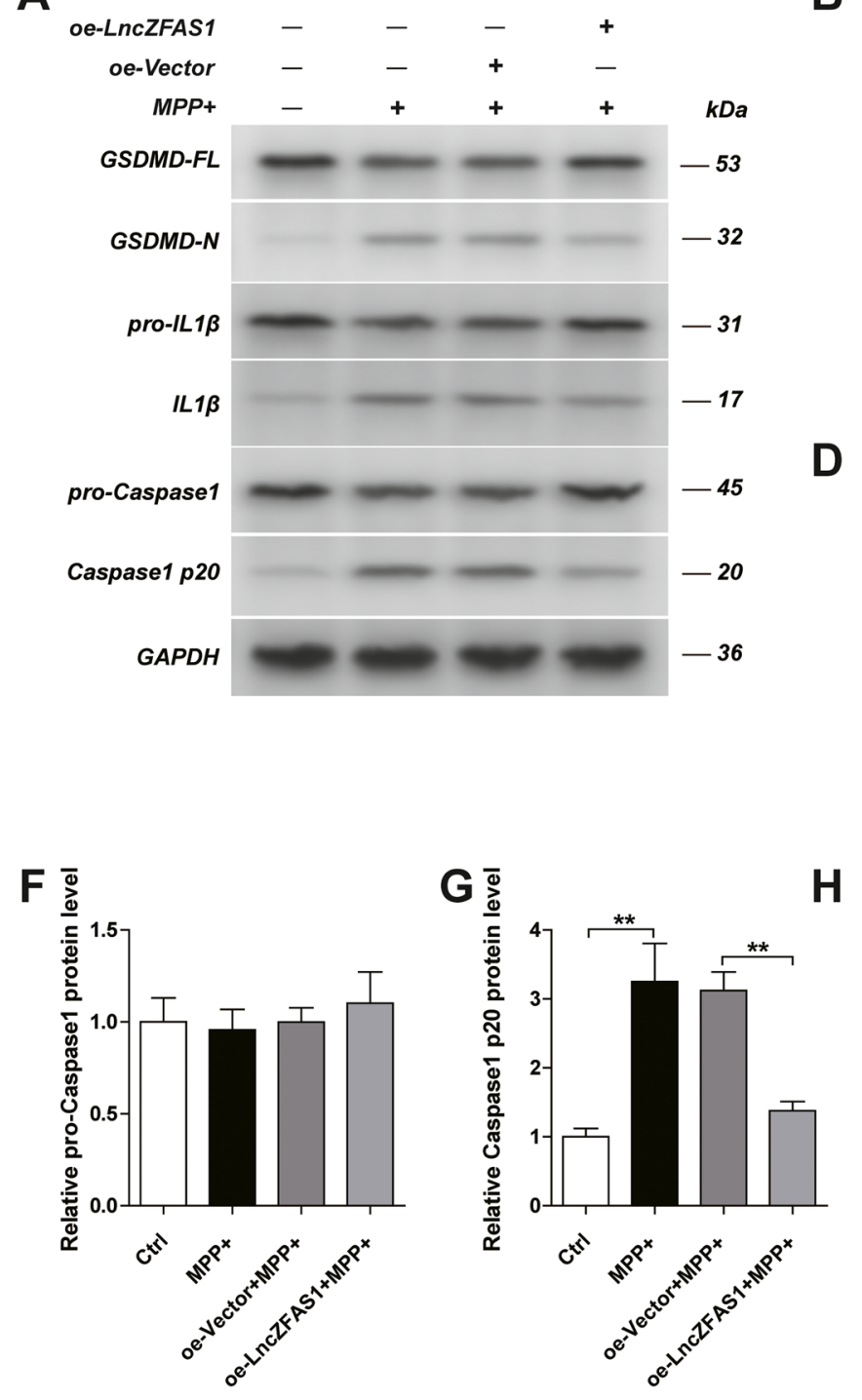

D
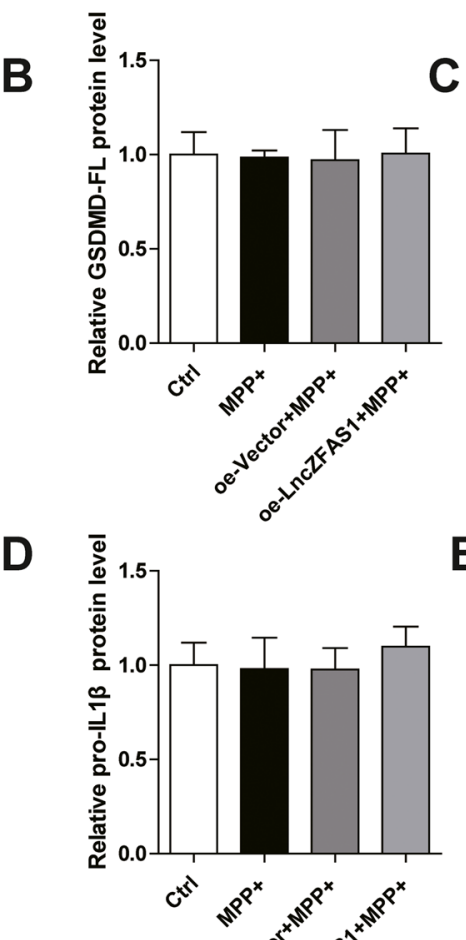

E
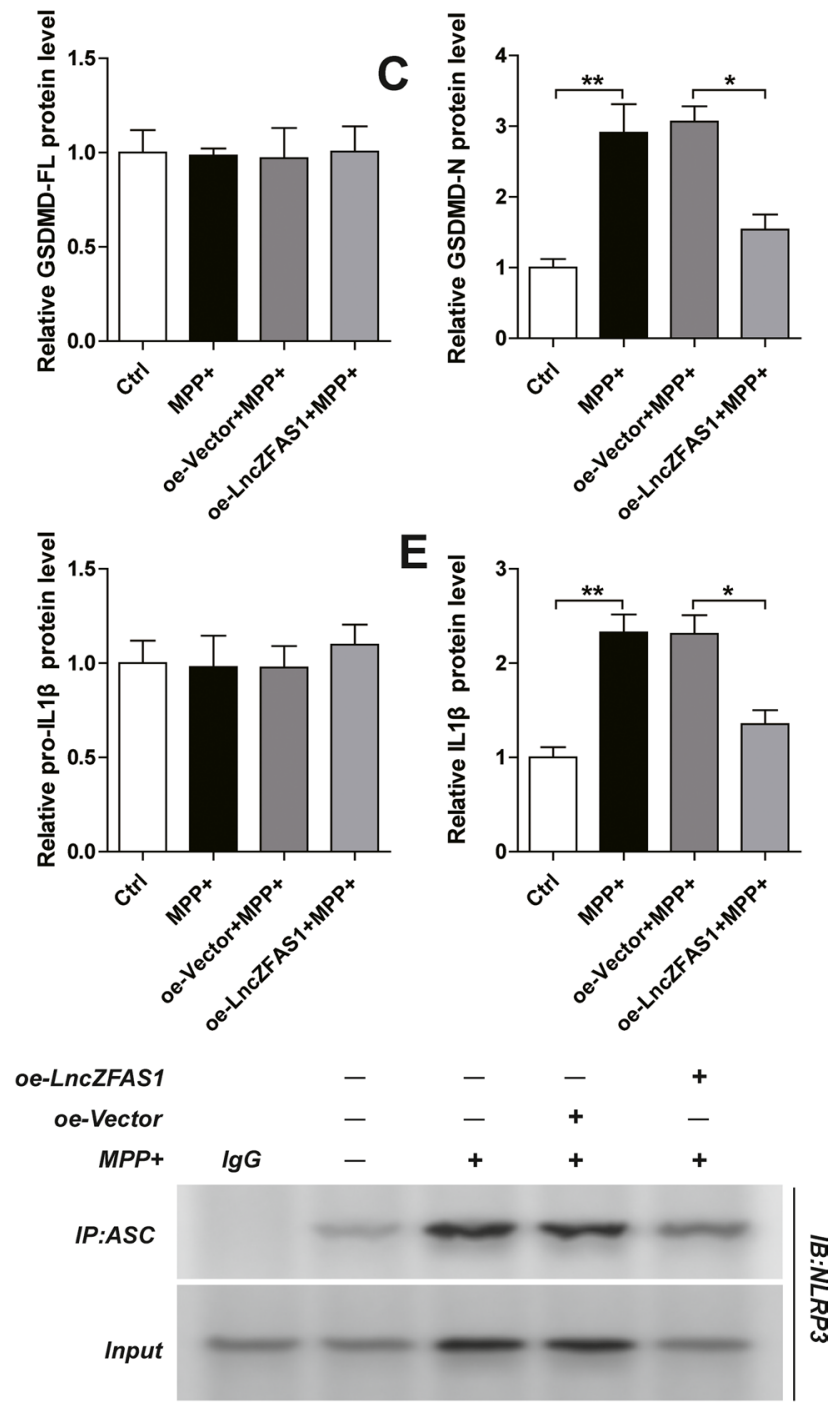

J
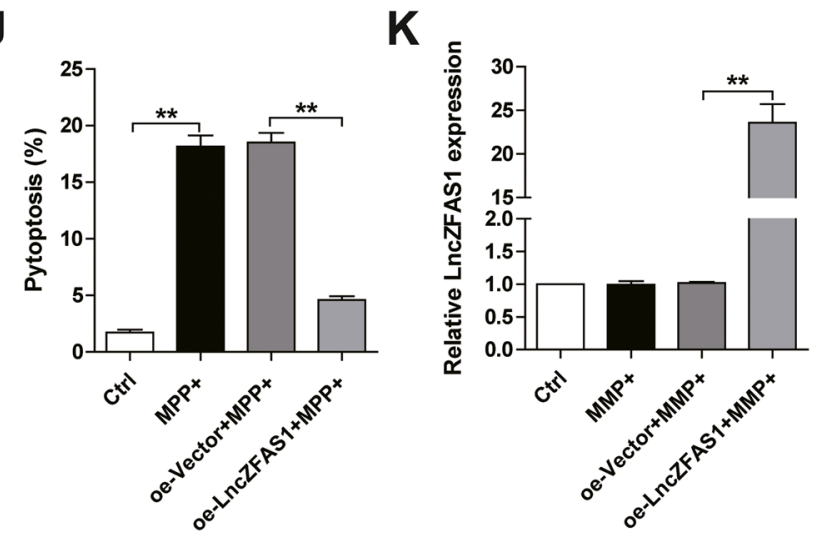
४Fig. 2 LncZFAS1 overexpression inhibited inflammasome activation and pyroptosis in SH-SY5Y cells. SH-SY5Y cells were stably transfected with lentiviral vector for LncZFAS overexpression or corresponding empty vector control. SH-SY5Y transfected cells were treated with $\mathrm{MPP}^{+}(1 \mathrm{mM})$ for $24 \mathrm{~h}$ and the expression of inflammasome effector proteins in SH-SY5Y cells detected by western blot assay (A). Relative expression of these proteins and their quantifications were shown respectively (B-G) (the same as followings). NLRP3/ASC interaction detected by immunoprecipitation with antiASC or control IgG antibody $(\mathbf{H})$. Frequency of pyroptotic SH-SY5Y transfected cells following $\mathrm{MPP}^{+}$treatment, measured by flow cytometry as described in Figure $1(\mathbf{I}, \mathbf{J})$. The expression of LncZFAS1 in the indicated group was measured by qPCR $(\mathbf{K})$. Data represented as mean $\pm \mathrm{SD}$ of three individual experiments for each condition, performed in triplicate. ${ }^{*} p<0.05,{ }^{*} p<0.01$

${ }^{\circ} \mathrm{C}$ and $5 \% \mathrm{CO}_{2}$ for $48 \mathrm{~h}$. Supernatants were collected $48 \mathrm{~h}$ after transfection, centrifuged at $4000 \mathrm{~g}$ for $10 \mathrm{~min}$ at $4{ }^{\circ} \mathrm{C}$ to remove cell debris, and transferred to 40 -mL ultracentrifuge tubes through a $0.45-\mu \mathrm{m}$ filter. Lentiviral particles were pelleted by ultracentrifugation at $25,000 \mathrm{rpm}, 4{ }^{\circ} \mathrm{C}$, for $2 \mathrm{~h}$, the media supernatant was discarded, and lentiviral particles were resuspended in the residual volume and transferred to a clean tube. Samples were centrifuged again at $10,000 \mathrm{rpm}$ for $5 \mathrm{~min}$, and the supernatant containing lentiviral particles was transferred to a clean tube. The lentivirus titer was detected in $293 \mathrm{~T}$ adherent cells. Cells were seeded in 96-well plates at $4 \times 10^{4}$ cells/well, in a $100 \mu \mathrm{L}$ medium and incubated for $24 \mathrm{~h}$. Lentiviral preps were serial diluted $(1 / 10)$ in serum free media $\left(10\right.$ to $\left.10^{-10}\right)$, added to T293 cells, and incubated at $37{ }^{\circ} \mathrm{C}$ and $5 \% \mathrm{CO}_{2}$ for $24 \mathrm{~h}$. Following incubation, $100 \mu \mathrm{L}$ of complete medium was added and the lentiviral titer measured after 4 days by fluorescence expression. The lentiviral titer was determined as transducing units $(\mathrm{TU} / \mathrm{mL})$ calculated as follows: $T U / m L=\frac{\frac{m+N}{100} * V * 1}{D F}$.

\section{Lentivirus Transfection}

SH-SY5Y cells were seeded in 24-well plates at $0.5 \times 10^{5}$ cells/well and incubated at $37{ }^{\circ} \mathrm{C}, 5 \% \mathrm{CO}_{2}$ overnight. Before transfection, cells were washed with PBS, and $500 \mu \mathrm{L}$ of $0.8 \mu \mathrm{g} / \mathrm{mL}$ polybrene in a serum-free medium with $20 \mu \mathrm{L}$ lentivirus at a pre-titrated MOI of 5 was added. Cells were incubated overnight at $37{ }^{\circ} \mathrm{C}$ and $5 \% \mathrm{CO}_{2}$, the medium was removed and replaced with $1 \mathrm{~mL}$ of complete medium, and further incubated at $37{ }^{\circ} \mathrm{C}$ and $5 \% \mathrm{CO}_{2}$. Transfected cells were expanded and subcultured at a 1:3 ratio. Forty-eight hours after subculture, cells were seeded in Petri dishes at $200 \mu \mathrm{g} / \mathrm{mL}$ puromycin; selection medium was changed every 3/4 days until clonal cell clusters appeared. Single cell clones were digested, transferred to 6-well plates, expanded, frozen, and stored in liquid nitrogen. Transfection efficiency was confirmed by western blot and qRT-PCR (Fig. S3).

\section{Luciferase Reporter Assay (pMIR-REPORT Fluorescent Reporter Gene)}

The 3'UTR full length of the pre-selected target gene MIB1 was identified based on the TargetScan Human 7.2 website (http:www.targetscan.org/vert_72/). Primer 5 (Premier, California) was used to design primers (Table 3 ) with the $3^{\prime}$ UTR fragment of the MIB1 gene containing the hsa-miR590-3p binding site. The MIB1 sequence (with 3'UTR) was then cloned in house into the pmiR-report plasmid (Ambion, TX, USA, Fig. S4) and expanded in E. coli DH5 $\alpha$ cells. First-strand cDNA reverse transcription from mRNA was performed using the iScript cDNA Synthesis Kit (BioRad, Hercules, CA, USA) as described above. The site directed mutagenesis was performed with a QuickMutagenesis Kit (Thermo Fisher Scientific, Pittsburgh, PA, USA) according to the manufacturer's recommendations. SH-SY5Y cells at 50\% confluency were then transfected in 96-well plates with Lipofectamine 3000 system (Thermo Fisher Scientific, Pittsburgh, PA, USA) according to the manufacturer's recommendations. Luciferase double reporter gene expression was detected with the dual luciferase reporter gene detection kit (KeyGEN Biotech, Nanjing, China) according to the manufacturer's recommendations. Briefly, after 36-48 $\mathrm{h}$ of plasmid co-transfection, the medium was discarded, and the cells washed with $100 \mu \mathrm{L} 1 \times$ PBS. Next, $50 \mu \mathrm{L}$ of $1 \times$ phosphate-buffered saline (PLB) was added to each well, and the plate was incubated for 20-30 min with shaking to ensure lysis. Subsequently, $10 \mu \mathrm{L}$ of the supernatant was added to a 96-well white opaque microtiter plate (Thermo Fisher, Pittsburgh, PA, USA), followed by $100 \mu \mathrm{L}$ of premixed Luciferase Assay Reagent II. Plates were read in a dark chamber with a Berthold LB941 microplate multifunctional microplate reader (Berthold, Germany) $2 \mathrm{~s}$ after starting the reaction to detect the luciferase activity (RLU1). Finally, $100 \mu \mathrm{L}$ of pre-mixed Stop\&Glo Reagent was then added to each well to detect the intensity of the luciferase reaction in the internal reference control (RLU2). The genespecific luciferase activity was calculated as RLU1/RLU2.

\section{miR590-3p Mimic and Inhibition Assay}

The hsa-miR-590-3p mimics (sequence: UAAUUUAUG UAUAAGCUAGU), mimic NC (sequence: UUGUACUAC ACAAAAGUACUG), hsa-miR-590-3p inhibitor (sequence: ACUAGCUUAUACAUAAAAUUA), and inhibitor-NC (sequence: CAGUACUUUUGUGUAGUACAA) particles were purchased from Nanjing Darn Pharmaceutical Technology Co., Ltd (Nanjing, China). SH-SY5Y cells at 50\% confluency were transfected into 6-well plates with Lipofectamine RNAiMAX (Thermo Fisher, Pittsburgh, PA, USA). In detail, Lipofectamine RNAiMAX ( $6 \mu \mathrm{L})$ and 20 pmol RNAi were mixed in $200 \mu \mathrm{L}$ OPTI-Minimal Essential 
A

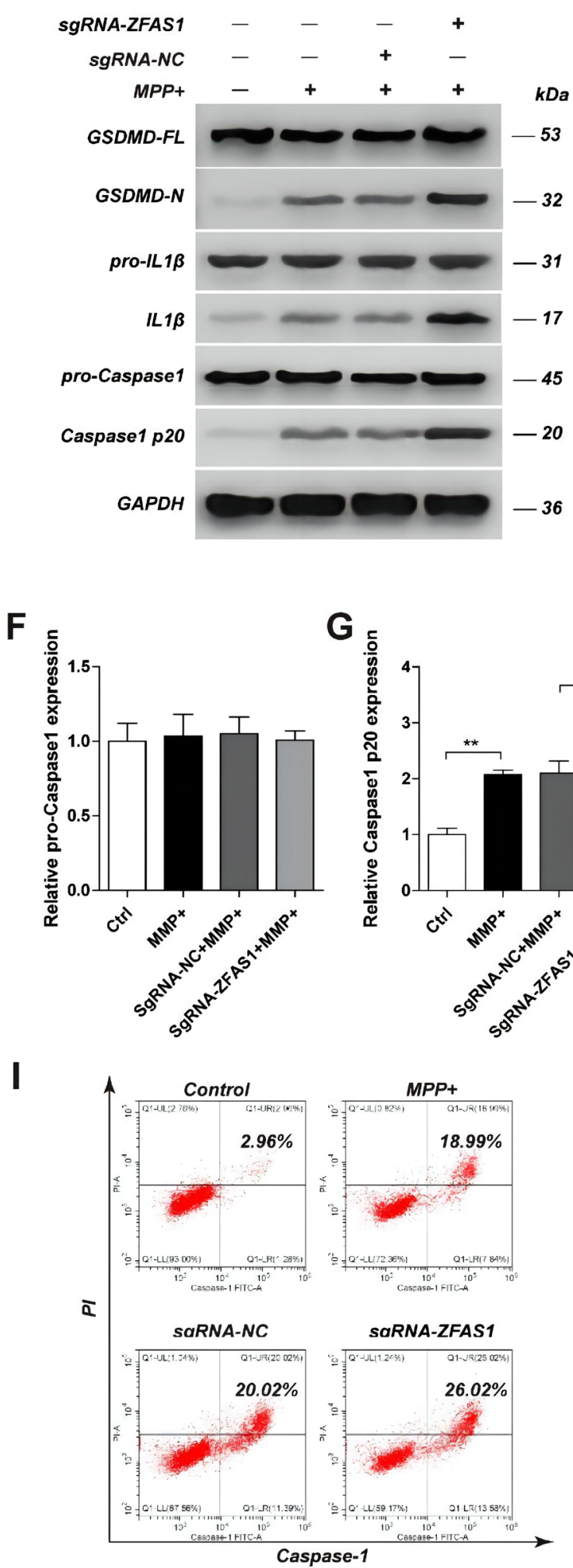

B

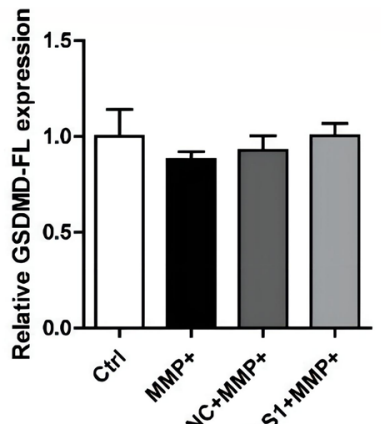

D

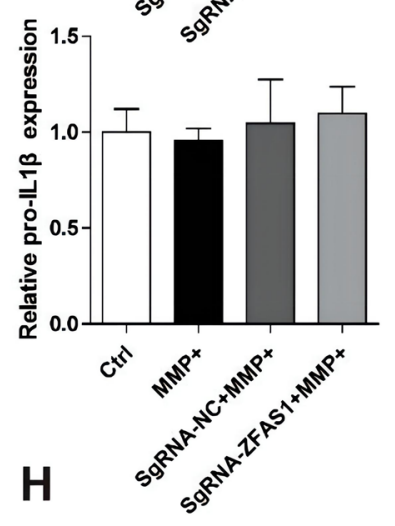

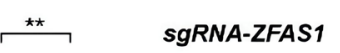

sgRNA-NC

MPP+ IgG -

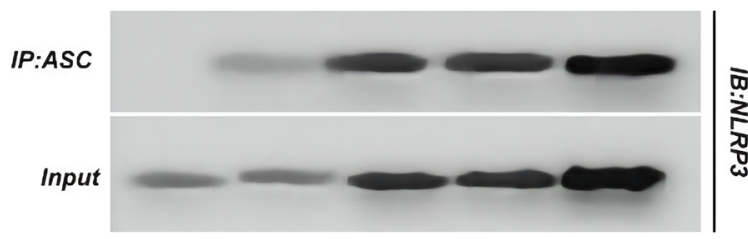

J

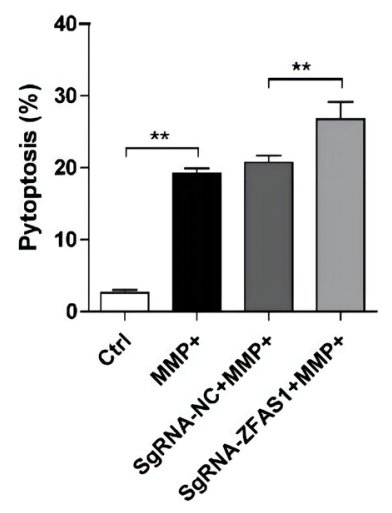

C

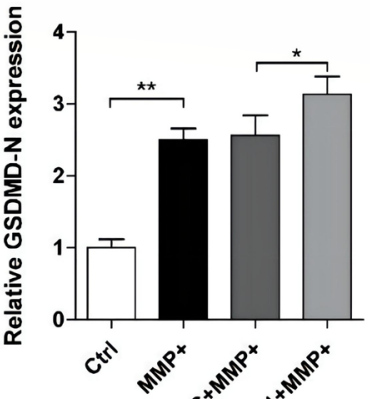

E

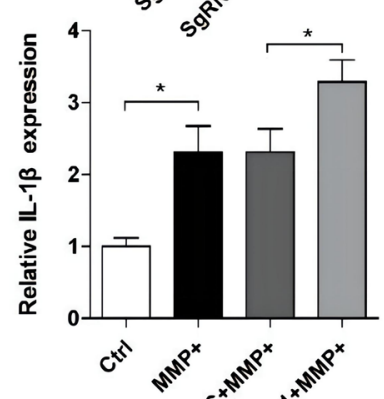

K

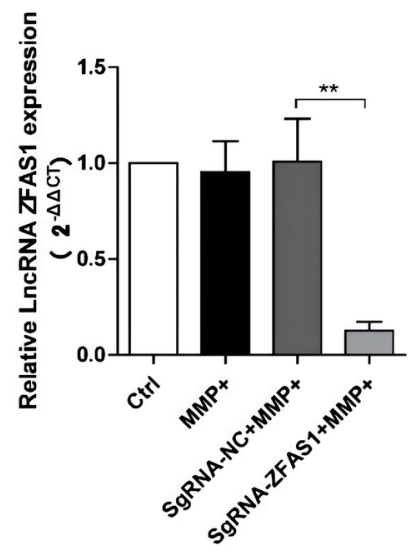


4Fig. 3 LncZFAS1 knockout induced inflammasome activation and pyroptosis in SH-SY5Y cells. LncZFAS1 was stably knockout by Crispr-cas9 plasmid in SH-SY5Y cells (sgRNA-ZFAS1) or corresponding negative control (sgRNA-NC), which were then treated with $\mathrm{MPP}^{+}(1 \mathrm{mM})$ for $24 \mathrm{~h}$. Expression of inflammasome effector proteins of SH-SY5Y transfected cells was detected by western blot assay (A), and their quantifications was shown respectively (B-G). Cell lysates were immunoprecipitated with anti-ASC antibody or control IgG followed by Co-IP assay to determine the interaction of Nlrp3 and ASC $(\mathbf{H})$. The pyroptosis ratio of SH-SY5Y cells in the indicated group was measured by flow cytometric analysis as above (I,J). The relative expression of LncZFAS1 was measured by qPCR (K). Data represented as mean \pm SD of three individual experiments for each condition, performed in triplicate. $* p<0.05$, ** $p<0.01$

Medium (OPTI-MEM, Thermo Fisher Scientific, Pittsburgh, PA, USA) and incubated at room temperature for $20 \mathrm{~min}$ before transfection. SH-SY5Y cells were gently washed with $1 \times$ PBS three times, $2 \mathrm{~mL}$ of OPTI-MEM medium was added to each well, and acclimated to $37{ }^{\circ} \mathrm{C}$ in $5 \% \mathrm{CO}_{2}$. Transfection reagent mixture was added to the culture with gentle shaking, followed by incubation at $37{ }^{\circ} \mathrm{C}, 5 \% \mathrm{CO}_{2}$ for $48 \mathrm{~h}$.

\section{Fluorescence In Situ Hybridization (FISH) and Confocal Microscopy}

The FISH staining kit was purchased from RiboBio (Guangzhou, China). Digoxin labeled probes (TACTTCCAACAC CCGCATTCATC) were acquired from RiboBio (Guangzhou, China). Briefly, $2 \times 10^{5} \mathrm{SH}-\mathrm{SY} 5 \mathrm{Y}$ cells were seeded onto 24-well microscopy slides (Thermo Fisher Scientific, Pittsburgh, PA, USA). After treatment, cells were washed with pre-cooled PBS and fixed with $4 \%$ RNase-free paraformaldehyde at room temperature for $15 \mathrm{~min}$. After washing with PBS three times for $5 \mathrm{~min}$, cells were permeabilized with $0.2-0.5 \%$ Triton X-100 for $5 \mathrm{~min}$ at room temperature. Cells were washed again with PBS $(3 \times 5 \mathrm{~min})$ and dehydrated (80-90-100\% alcohol gradient for 2-3 min each). The hybridization solution was prepared in house with formamide mixed with $2 \times$ saline-sodium citrate (SSC) at a 1:1 volume at room temperature for $10 \mathrm{~min}$. Cells were washed again with PBS, and $25 \mu \mathrm{L}$ of hybridization solution was added to each well and incubated in the hybridization furnace at $50{ }^{\circ} \mathrm{C}$ for $4-8 \mathrm{~h}$. Following incubation, $60 \mu \mathrm{L}$ of denaturing hybridization solution containing probe was added to each well and incubated overnight in the hybridization
Fig. 4 LncZFAS1 overexpression blocked $\mathrm{MPP}^{+}$-induced oxidative stress through TRX1/TXNIP redox signaling complex. SH-SY5Y cells were stably transfected with lentiviral vector for LncZFAS overexpression or corresponding empty vector control. SH-SY5Y transfected cells were treated with $\mathrm{MPP}^{+}(1 \mathrm{mM})$ for $24 \mathrm{~h}$, and intracellular ROS production level was measured by flow cytometry (A and B). Protein and transcriptional expression of TXNIP was detected by western blot assay $(\mathbf{C}, \mathbf{D})$ or qRT-PCR (E). TXNIP/ TRX1 interaction was detected by immunoprecipitation with anti-TRX1 antibody or control $\operatorname{IgG}(\mathbf{F})$. Data represented as mean \pm SD of three individual experiments for each condition, performed in triplicate. ${ }^{*} p<$ $0.05, * * p<0.01$
A

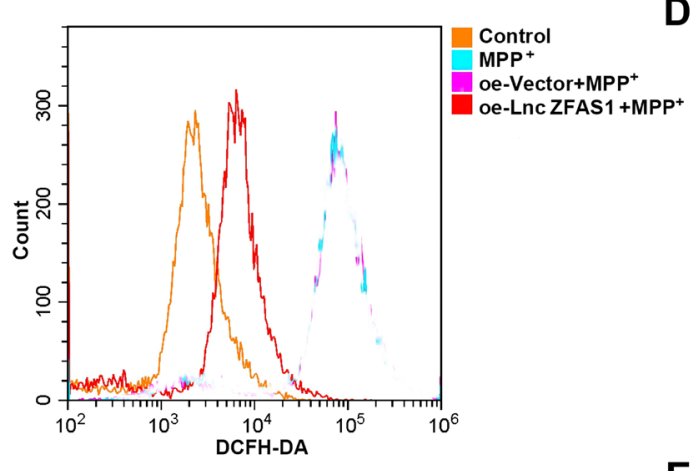

B

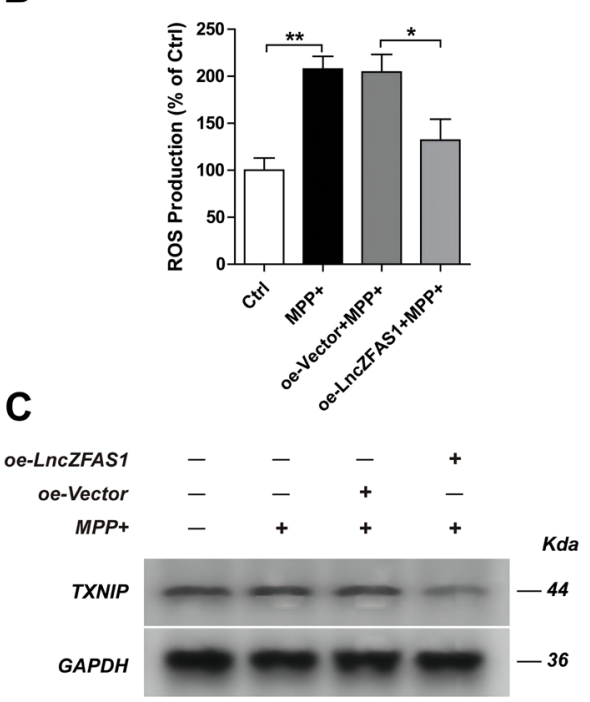

E

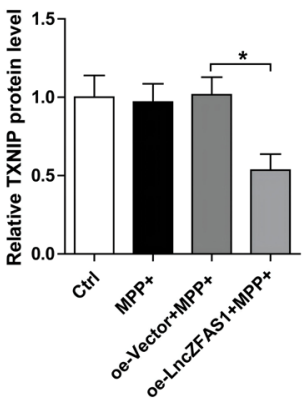

D

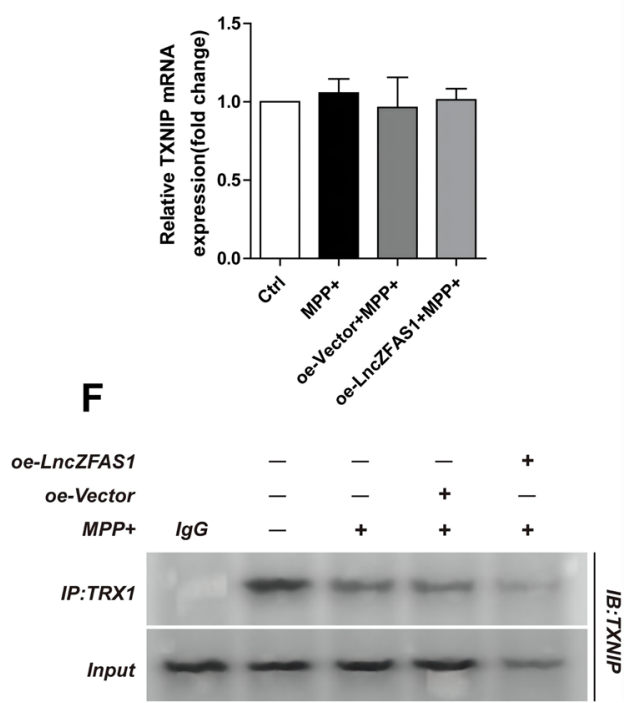


Fig. 5 LncZFAS1 knockout enhances $\mathrm{MPP}^{+}$-induced oxidative stress through TRX1/TXNIP redox signaling complex. LncZFAS1 was stably knockout by Crispr-cas9 plasmid in SH-SY5Y cells (sgRNA-ZFAS1) or corresponding negative control (sgRNA$\mathrm{NC})$, which were then treated with $\mathrm{MPP}^{+}(1 \mathrm{mM})$ for $24 \mathrm{~h}$. The expression of TXNIP (A, B) was detected by western blot assay, and the cell lysates were immunoprecipitated with anti-TRX1 antibody or control $\mathrm{IgG}$ followed by Co-IP assay to determine the interaction of TXNIP and TRX1 (C). TXNIP mRNA levels of the indicated groups were measured by qPCR (D). ROS production of sgRNAZFAS1 SH-SY5Y cells was measured by flow cytometric analysis $(\mathbf{E}-\mathbf{F})$. Data represented as mean \pm SD of three individual experiments for each condition, performed in triplicate. $* p<0.05, * * p<0.01$
A

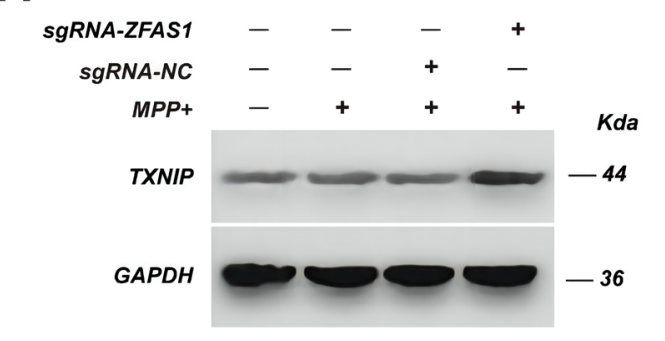

C

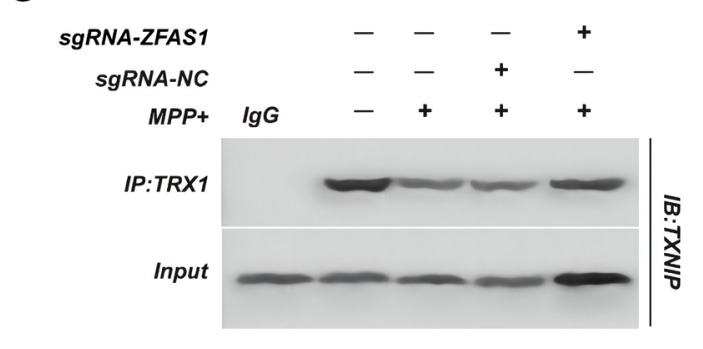

$\mathbf{E}$

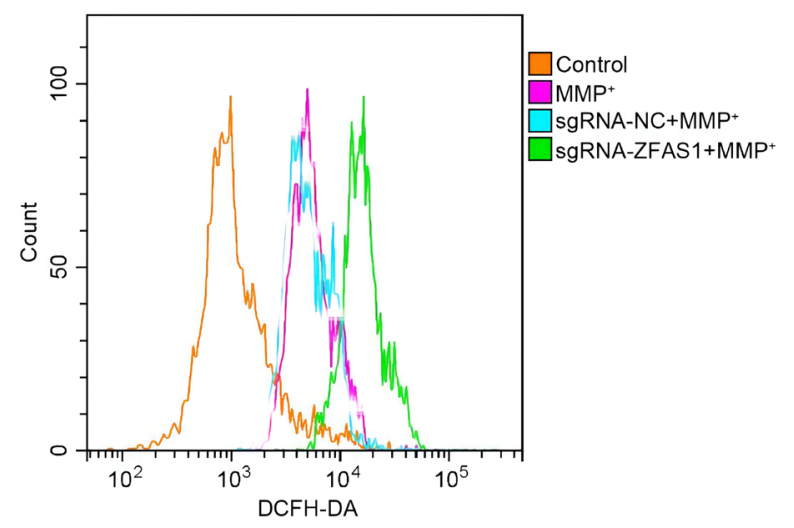

B
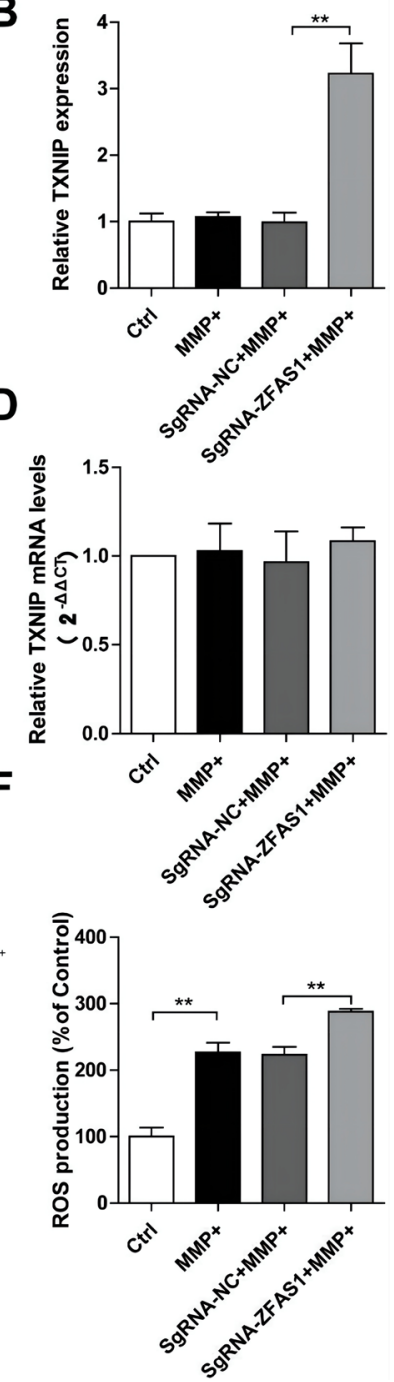

furnace at $50{ }^{\circ} \mathrm{C}$. Following incubation, the cells were washed with $0.1 \times \mathrm{SSC}$ with $0.1 \% \mathrm{SDS}$ and $50 \%$ formamide for $30 \mathrm{~min}$. The samples were then blocked with $90 \mu \mathrm{L} 20 \%$ sheep serum at room temperature for $1 \mathrm{~h}$. Hybridization was detected with $60 \mu \mathrm{L}$ anti-digoxin antibody, prepared 1/2500 in $10 \%$ sheep serum, and incubated overnight at $4{ }^{\circ} \mathrm{C}$. After washing with PBS, samples were counterstained with 10 $\mu \mathrm{L}$ of $200 \mathrm{mg} / \mathrm{mL}$ DAPI at room temperature for $10 \mathrm{~min}$. Cells were washed once with PBS, mounted with $10 \mu \mathrm{L}$ anti-quenching mounting agent, sealed with rubber cement, and imaged using a Zeiss LSM laser confocal microscope (Zeiss, Germany).

\section{Statistical Analysis}

All data are expressed as the mean \pm SD. One-way ANOVA and non-parametric Kruskal-Wallis test were used to examine the statistical differences between groups. $p$ values $<$ 0.05 were considered to indicate significant differences. Data were analyzed with GraphPad Prism 6.0 (San Diego, CA, USA).

\section{Results}

\section{$\mathrm{MPP}^{+}$Induced Pyroptosis Through Inflammasome Activation in SH-SY5Y Neuronal Cells}

NLRP3 inflammasome activation and pyroptosis in primary microglial cells were found to be pivotal for MTPTinduced Parkinson's disease progression in a murine model[17]. To determine whether $\mathrm{MPP}^{+}$can also induce inflammasome activation and pyroptosis in human neuroblast cells, SH-SY5Y cells were treated with $\mathrm{MPP}^{+}$in increasing concentrations, and the frequency of pyroptotic cells was quantified by PI internalization and caspase-1 activation. As expected, $\mathrm{MPP}^{+}$treatment with increasing MTPT concentrations of $250 \mathrm{nM}$ to $1 \mathrm{mM}$ significantly 


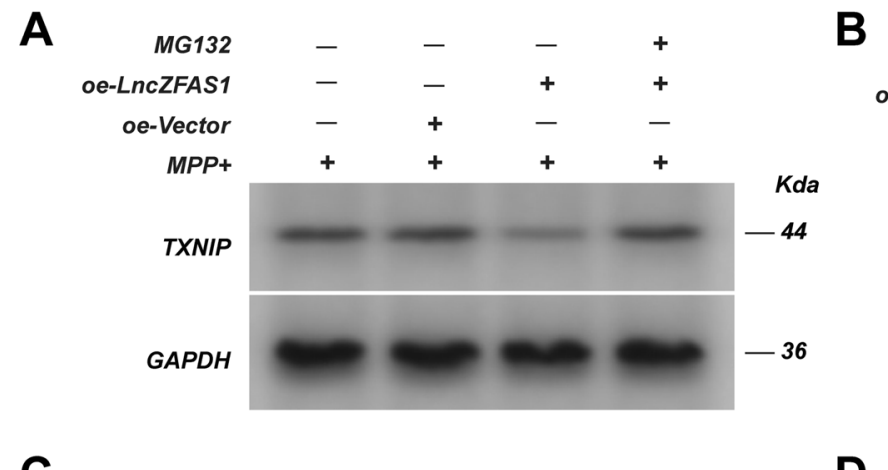

C

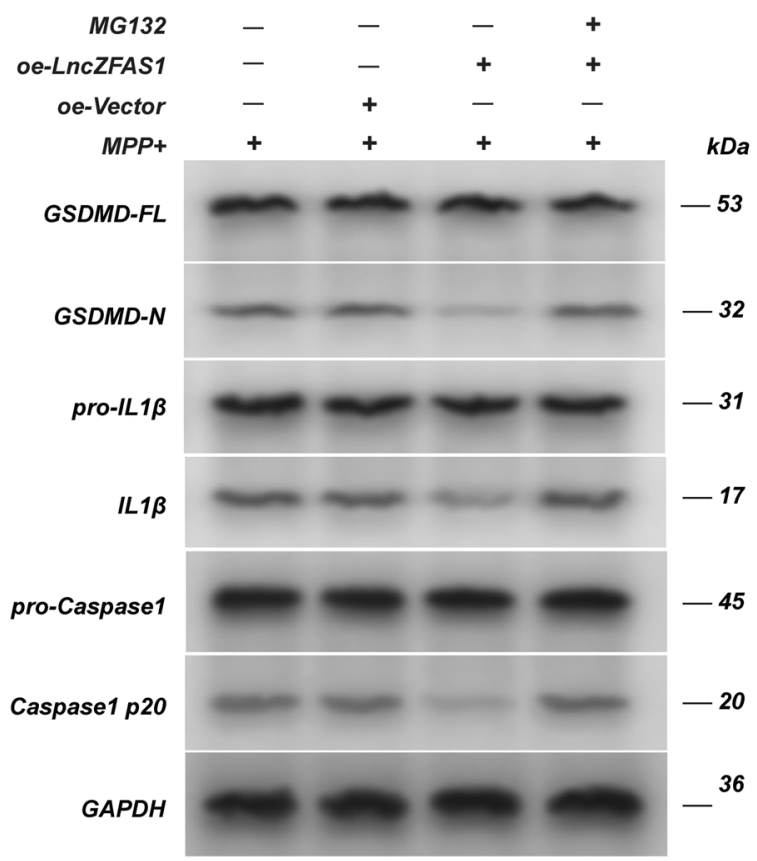

H

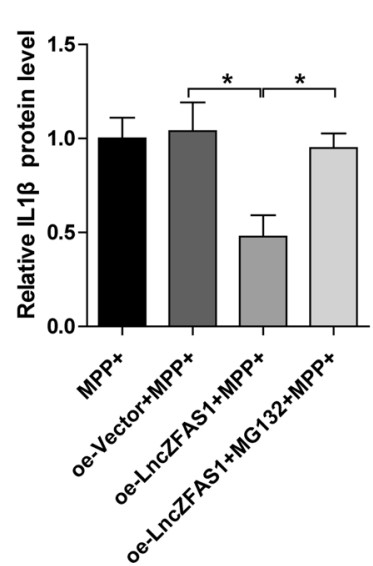

Fig. 6 LncZFAS1 overexpression inhibited inflammasome activation through TXNIP proteasomal degradation. SH-SY5Y cells were stably transfected with lentiviral vector for LncZFAS overexpression or corresponding empty vector control. SH-SY5Y transfected cells were treated with $\mathrm{MPP}^{+}(1 \mathrm{mM})$ or co-treated with MG132 $(1 \mu \mathrm{M})$ for $24 \mathrm{~h}$ and the expression of TXNIP (A) and inflammasome effec-
B
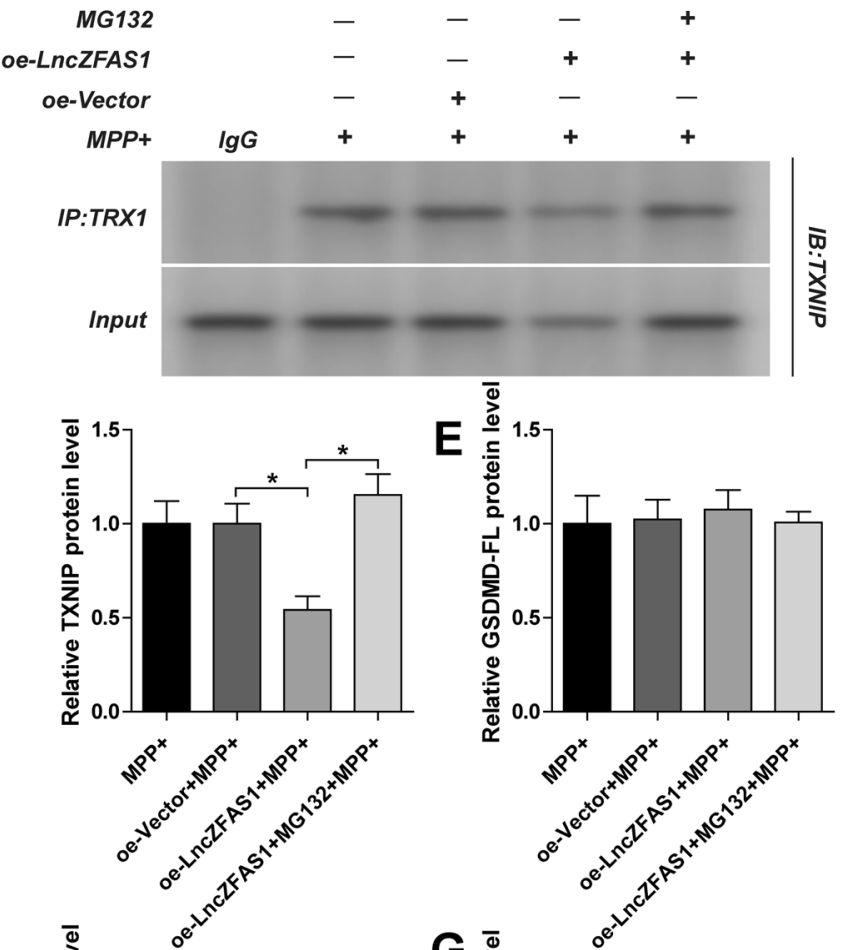

\section{F}

竎
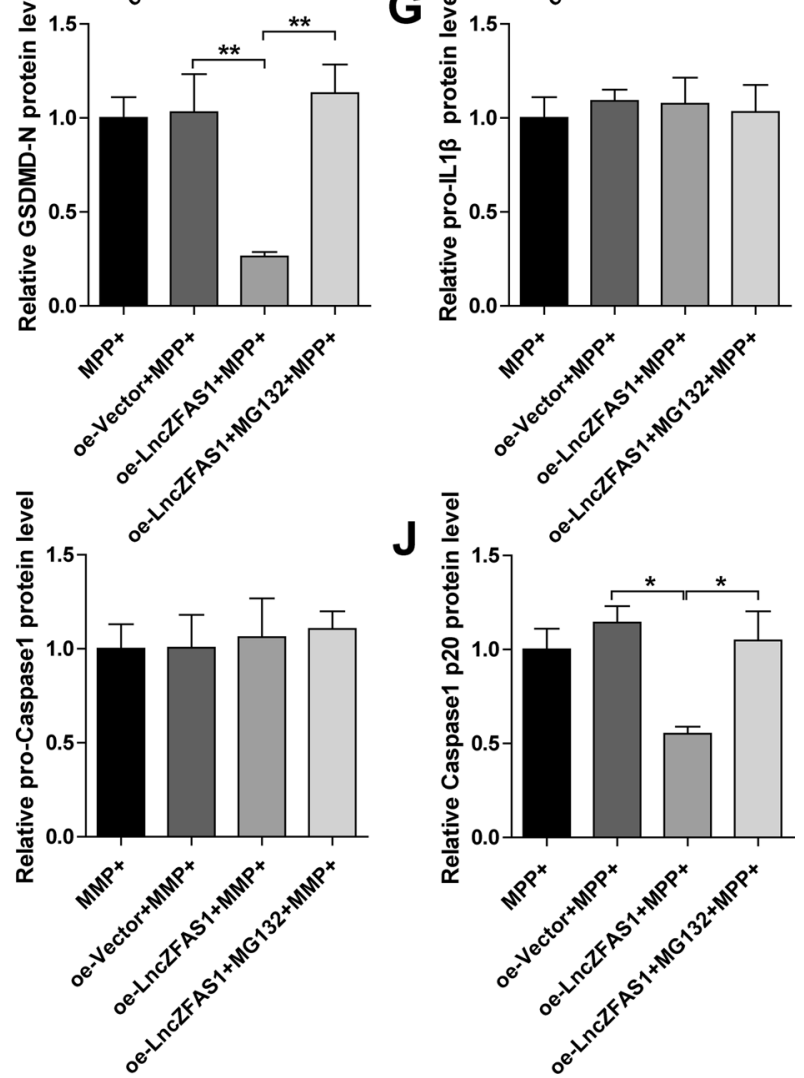

tor proteins were detected by western blot assay $(\mathbf{C})$, and their quantifications were shown $(\mathbf{C}-\mathbf{J})$. TXNIP/TRX1 interaction was detected by immunoprecipitation with anti-TRX1 or control IgG antibody (B). Data represented as mean \pm SD of three individual experiments for each condition, performed in triplicate. ${ }^{*} p<0.05,{ }^{* *} p<0.01$ 


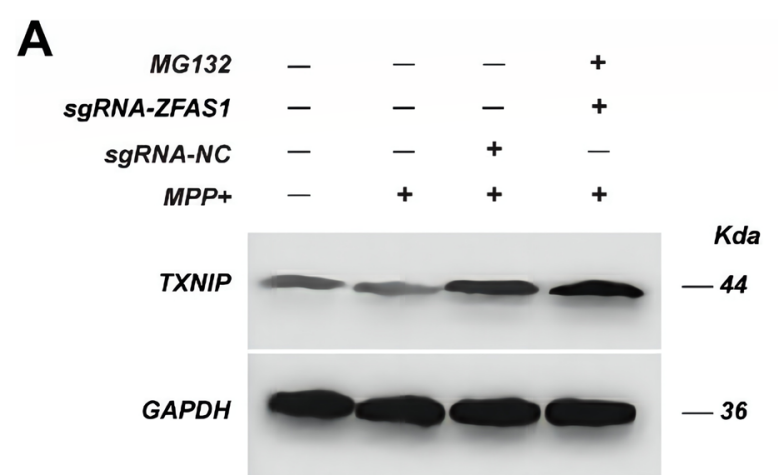

B
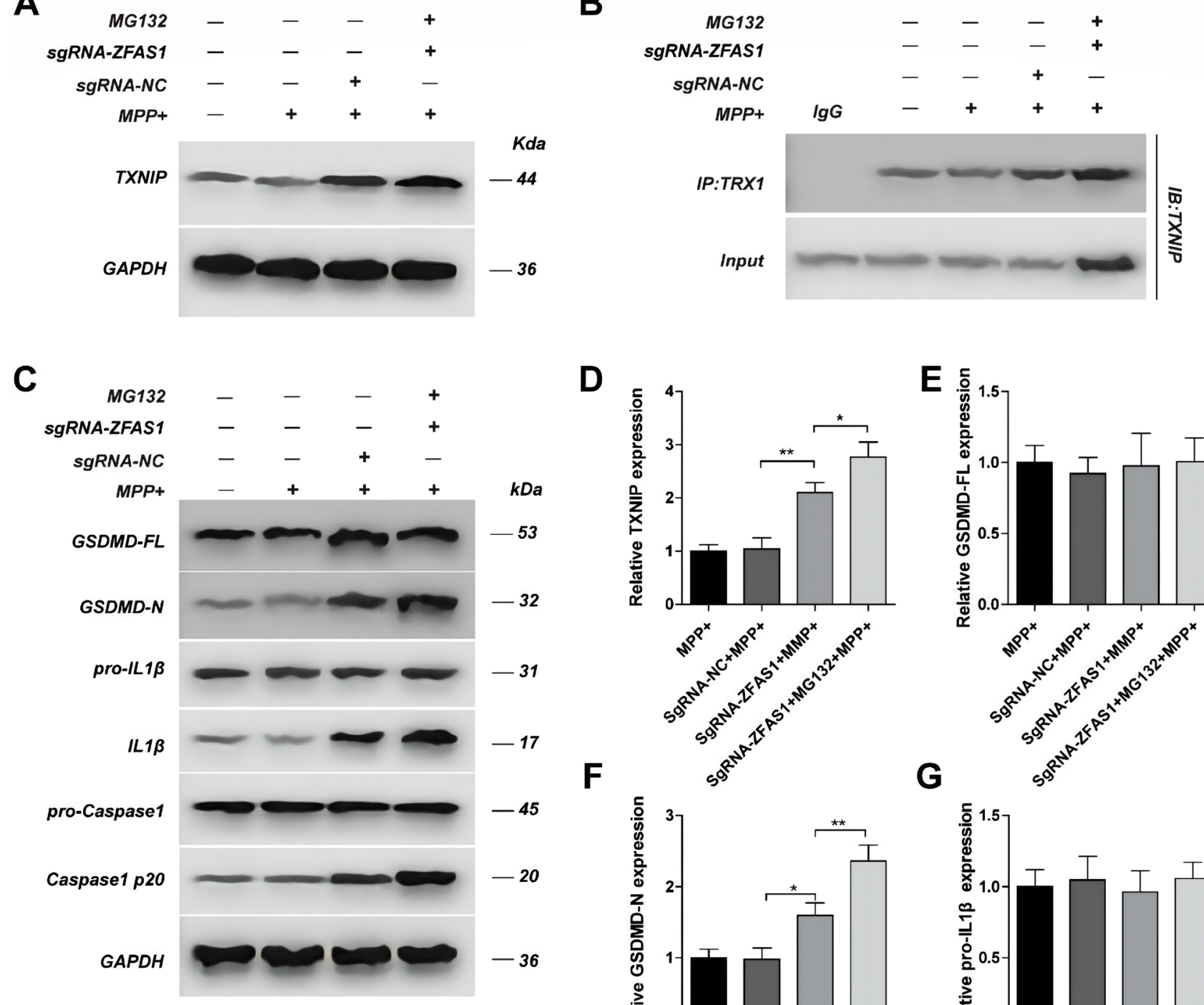

D

F

H

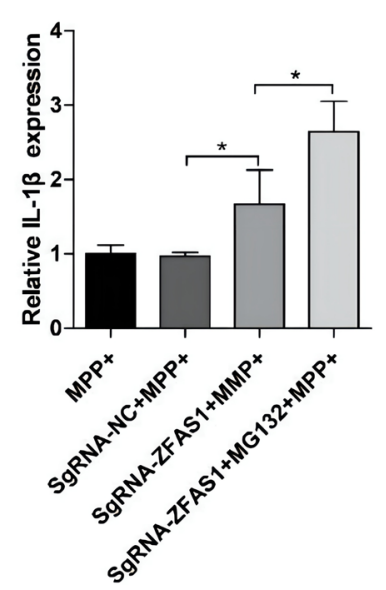

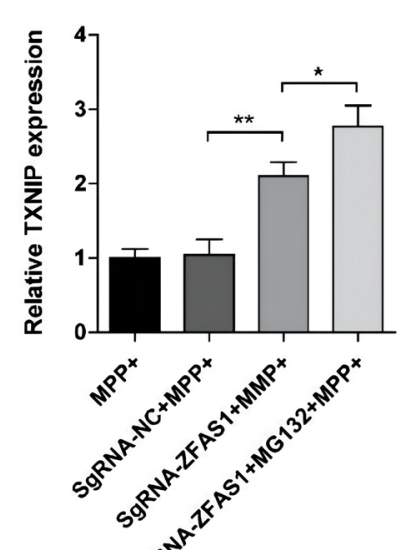

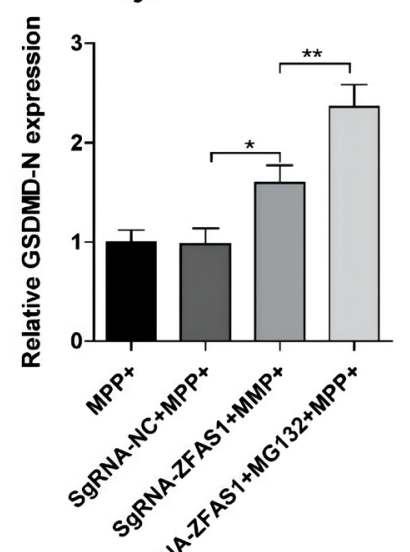

E
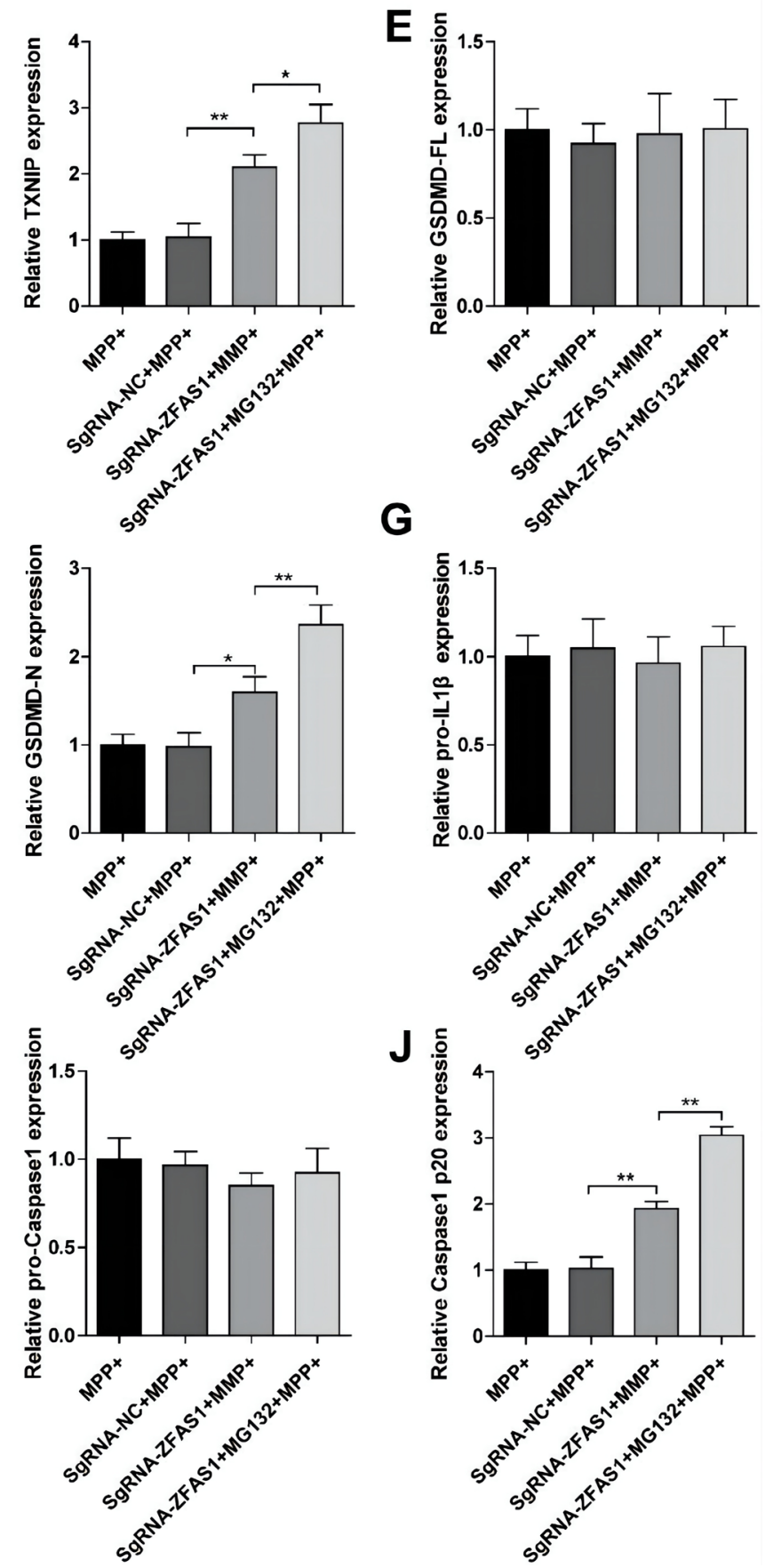
4Fig.7 LncZFAS1 knockout increased TXNIP expression in $\mathrm{MPP}^{+}$-treated SH-SY5Y cells. LncZFAS1 was stably knockout by Crispr-cas9 plasmid in SH-SY5Y cells (sgRNA-ZFAS1) or corresponding negative control (sgRNA-NC), which were then treated with $\mathrm{MPP}^{+}(1 \mathrm{mM})$ or co-treated with MG132 $(1 \mu \mathrm{M})$ for $24 \mathrm{~h}$. The expression of TXNIP (A), inflammasome effector proteins of transfected cells were detected by western blot assay (C) and their responding quantification was shown respectively (D-J). TXNIP/ TRX1 interaction was detected by immunoprecipitation with antiTRX1 or control IgG antibody (B). Data represented as mean \pm SD of three individual experiments for each condition, performed in triplicate. ${ }^{*} p<0.05, * * p<0.01$

increased the frequency of pyroptotic SH-SY5Y cells $24 \mathrm{~h}$ after treatment (Fig. 1A, B). Furthermore, $\mathrm{MPP}^{+}$treatment significantly induced NLPR3/ASC association and cleavage of Gsdmd, pro-IL-1 $\beta$, and caspase-1, all hallmarks of inflammasome activation. $\mathrm{MPP}^{+}$had no impact on the protein levels of Gsdmd, pro-IL-1 $\beta$, and caspase- 1 precleaved peptides (Fig. 1C, D).

\section{LncZFAS1 Inhibited MPP ${ }^{+}$-Induced Pyroptosis in SH-SY5Y Human Neuroblasts}

MicroRNA and LncRNA regulate a myriad of metabolic and inflammatory pathways, including inflammasome activation[25]. The role of LncZFAS in the inflammasome and pyroptosis has not yet been addressed. Therefore, to understand the impact of ZFAS in $\mathrm{MPP}^{+}$-induced pyroptosis, IncZFAS was stably transfected into SH-SY5Y cells before $\mathrm{MMP}^{+}$treatment (Fig. S3). LncZFAS1 overexpressing (oe-LncZFAS1) cells showed significantly lower cleavage of Gsdmd, pro-IL-1 $\beta$, and caspase- 1 following $\mathrm{MPP}^{+}$ treatment compared to the empty vector transfected control cells (oe-vector), although there was no impact on the overall pre-cleaved peptide levels (Fig. 2A-G). Moreover, oe-LncZFAS 1 cells had lower NRLP3/ASC association than oe-vector cells $24 \mathrm{~h}$ after $\mathrm{MPP}^{+}$treatment (Fig. $2 \mathrm{H}$ ). Consequently, oe-LncZFAS1 SH-SY5Y cells were resistant to $\mathrm{MPP}^{+}$-induced pyroptosis (Fig. 2I-K).

To confirm the role of lncZFAS on $\mathrm{MMP}^{+}$-induced pyroptosis, lncZFAS was stably knocked-out in SH-SY5Y cells (sgRNA-ZFAS1) (Fig. 3). MPP $^{+}$-treated sgRNAZFAS 1 cells showed significantly higher cleavage of Gsdmd, pro-IL-1 $\beta$, and caspase- 1 than $\mathrm{MPP}^{+}$-treated control cells, although there was no impact on the overall precleaved peptide levels (Fig. 3A-G). Additionally, sgRNAZFAS1 cells had higher NRLP3/ASC association than sgRNA-NC cells $24 \mathrm{~h}$ after $\mathrm{MPP}^{+}$treatment (Fig. $3 \mathrm{H}$ ). Finally, sgRNA-ZFAS1 cells showed higher sensitivity to $\mathrm{MPP}^{+}$-induced pyroptosis (Fig. 3I-K).

\section{LncZFAS1 Blocked MPP ${ }^{+}$-Induced Oxidative Stress Through the TRX1/TXNIP Redox Signaling Complex}

Increased intracellular oxidative stress may act as second signal for NLRP3 inflammasome activation[18, 21-23]. To determine whether $\mathrm{MPP}^{+}$induces intracellular oxidative stress in SH-SY5Y cells, intracellular ROS was measured using a DCFH-DA ROS-sensing fluorescent probe and analyzed by flow cytometry. As expected, $\mathrm{MPP}^{+}$significantly induced intracellular ROS in SH-SY5Y human neuroblasts $24 \mathrm{~h}$ after treatment (Fig. 4A, B). Furthermore, to determine whether LncZFAS1 inhibits $\mathrm{MPP}^{+}$-induced oxidative stress, oe-SHSY5Y cells were treated with $\mathrm{MPP}^{+}$, and the intracellular ROS-levels were measured $24 \mathrm{~h}$ after treatment. Again, as hypothesized, LncZFAS1 overexpression significantly decreased intracellular oxidative stress compared to corresponding empty vector transfected control cells (Fig. 4A, B).

Increased oxidative stress activates the NLRP3 inflammasome through induction and activation of the TXNIP redox-sensing complex, but the defined molecular mechanism remains elusive[37, 38]. In SH-SY5Y cells, $\mathrm{MPP}^{+}$did not change the TXNIP protein transcriptional and translational levels (Fig. 4C-E), nor did it change the TXNIP/ TRX1 interaction (Fig. 4F). In contrast, LncZFAS1 significantly decreased post-translational TXNIP protein levels (Fig. 4C-E) with a prominent decrease in the TXNIP/TRX1 interaction (Fig. 4F).

To further validate the impact of the LncZFAS1 TXNIP redox-sensing complex in response to $\mathrm{MPP}^{+}$, the expression levels of TXNIP/TRX1 were measured in sgRNA-ZFAS1 cells. LncZFAS1 knockout significantly increased TXNIP protein levels but did not impact the transcriptional levels (Fig. 5A, B, and D). Moreover, after immunoprecipitation with an anti-TXNIP antibody, MPP $^{+}$-treated sgRNA-ZFAS1 cells showed increased interaction with TRX1 compared to sgRNA-NC cells, likely due to increased TXNIP protein levels (Fig. 5C). Finally, to confirm that LncZFAS1 regulates the intracellular oxidative stress response to $\mathrm{MPP}^{+}$, ROS levels were measured in sgRNA-ZFAS1 cells and corresponding sgRNA-NC cells $24 \mathrm{~h}$ after $\mathrm{MPP}^{+}$stimulation. In accordance with our previous observations, LncZFAS1 knockout significantly induced intracellular ROS production following MPP+ stimulation in SH-SY5Y cells (Fig. 5E, F).

\section{LncZFAS1 Inhibited Inflammasome Activation Through TXNIP Proteasomal Degradation}

The proteasomal degradation pathway has been recently identified as a major regulator of inflammasome activation[39]. To determine whether LncZFAS1 post-translationally downregulates TXNIP through the proteasome degradation pathway, oe-ZFAS1 cells were treated with $\mathrm{MPP}^{+}$and the MG132 proteasome inhibitor. As expected, proteasomal 


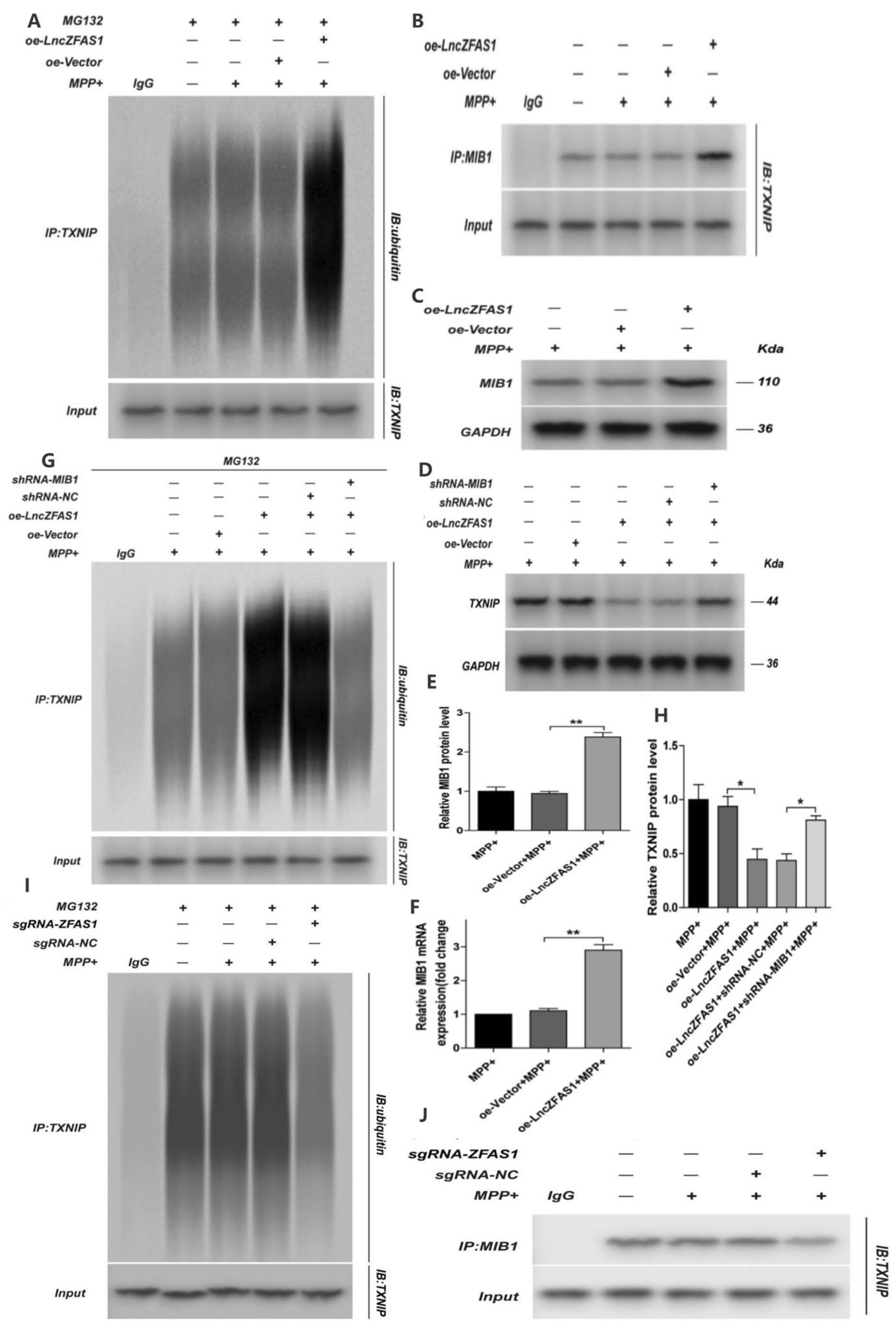


४Fig. 8 LncZFAS1 regulated TXNIP ubiquitination. SH-SY5Y cells were stably transfected with lentiviral vector for LncZFAS overexpression or corresponding empty vector control. Transfected cells were then treated with $\mathrm{MPP}^{+}(1 \mathrm{mM})$ or co-treated with MG132 (1 $\mu \mathrm{M})$ for $24 \mathrm{~h}$, and specific ubiquitination was assessed by immunoprecipitation with anti-TXNIP antibody, followed by immunoblot with anti-ubiquitin antibody (A). TXNIP/MIB1 interaction was determined by immunoprecipitation with anti-MIB1 or control IgG antibody (B). MIB1 expression was quantified by western blot $(\mathbf{C}, \mathbf{E})$ and qRT-PCR (F). A, B, C, G, and $\mathrm{H}$ results were representative of three independent experiments. LncZFAS1 stably knockout SH-SY5Y cells (sgRNA-ZFAS1) were treated with $\mathrm{MPP}^{+}(1 \mathrm{mM})$ or co-treated with MG132 $(1 \mu \mathrm{M})$ for $24 \mathrm{~h}$ and cell extracts immunoprecipitated with anti-TXNIP antibody, followed by immunoblot with anti-ubiquitin antibody (I). TXNIP/MIB1 interaction was detected by immunoprecipitation with anti-MIB1 antibody or control $\operatorname{IgG}(\mathbf{J})$. Data represented as mean \pm SD of three individual experiments for each condition, performed in triplicate. $* p<0.05, * * p<0.01$

inhibition rescued TXNIP protein levels and TXNIP/TRX1 interactions in oe-ZFAS SY-SH5Y neuroblasts (Fig. 6A, B, $\mathrm{D}$, and E). Consistent with the role of TXNIP in NLRP3 inflammasome activation, proteasomal inhibition rescued cleavage of Gsdmd, pro-IL-1 $\beta$, and caspase-1 (Fig. 6C, F, $\mathrm{H}$, and $\mathrm{J}$ ), all of which are hallmarks of inflammasome activation in oe-ZFAS SY-SH5Y cells following $\mathrm{MPP}^{+}$treatment. Proteasome inhibition had no impact on the protein levels of Gsdmd, pro-IL-1 $\beta$, and caspase-1 pre-cleaved peptides (Fig. 6C, G, and I), while the opposite results were observed after LNCZFAS1 knockout (Fig. 7). Moreover, sgRNA-ZFAS1 cells showed increased TXNIP expression and TXR1 association even after treatment with the MG132 proteasome inhibitor (Fig. 7A, B), which resulted in increased inflammasome activation (Fig. 7C, D, F, H, and J). Nonetheless, LncZFAS1 knockout did not affect pre-cleaved levels of Gsdmd, pro-IL-1 $\beta$, and caspase-1 (Fig. 7E, G, and I), again indicative of proteasomal regulation of the activated inflammasome.

\section{LncZFAS1 Induced TXNIP Proteosomal Degradation Through MIB1 Ubiquitination}

Proteasomal degradation is mainly regulated by the ubiquitin system[39]. Hence, the levels of TXNIP ubiquitination in oe-LncZFAS1 SH-SY5Y cells were assessed by Co-IP and western blotting (Fig. 8A). oe-LncZFAS1 cells showed higher TXNIP association with E3 ubiquitin ligase protein MIB1 following $\mathrm{MPP}^{+}$treatment (Fig. 8B). Moreover, LncZFAS1 overexpression significantly induced MIB1 transcriptional and protein levels in SH-SY5Y cells following $\mathrm{MPP}^{+}$treatment (Fig. 8C, E, and F). To verify that LncZFAS1-induced TXNIP ubiquitination depends on the MIB1 protein interaction, a MIB1 knockdown SH-SY5Y cell line was generated on the oe-ZFAS1 background (Fig. S3). MIB1 knockdown was shown to rescue TXNIP protein levels in oe-ZFAS1 cells and reduced TXNIP ubiquitination following $\mathrm{MPP}^{+}$treatment (Fig. 8D, G, and H). In contrast, transfection with lentiviral scramble control had no impact on TXNIP protein levels or ubiquitination (Fig. 8G-H). A series of similar experiments was conducted with sgRNAZFAS1 cells, showing decreased TXNIP ubiquitination and MIB1 association (Fig. 8I, J).

\section{LncZFAS1 Interferes with miR590-3p-Mediated MIB-1 Downregulation}

miRs are single small non-coding RNAs that regulate gene expression of a myriad of protein targets[40]. LncZFAS1 significantly downregulates miR590-3p, a putative regulator of MIB1 (Fig. 9A). To determine whether miR590-3p regulates MIB 1 expression, SH-SY5Y cells were treated with a miR590-3p or a miR590-3p inhibitor and respective negative controls, and MIB1 protein levels were assessed by western blot. Consistent with the in silico predictions, miR590-3p treatment prominently decreased MIB1 protein expression. In contrast, the miR590-3p inhibitor greatly increased MIB1 protein levels (Fig. 9A, B). MiR regulated protein expression post-transcriptionally through direct binding to the 3 '-untranslation region ( $3^{\prime}$ UTR), inducing translation inhibition or mRNA degradation of their targets. Consistent with this mechanism, SH-SY5Y cells treated with miR590-3p had significantly lower MIB1 mRNA transcripts, while miR590-3p inhibition significantly increased MIB1 transcriptional expression (Fig. 9C). To validate direct miR590-3p binding to the 3'UTR, a MIB1 luciferase reporter system was generated with the WT MIB1 3'UTR (WT-MIB1) or a miR590$3 p$ resistant 3'UTR (mut-MIB1) (Fig. 9D). Consistent with the transcriptional data, miR590-3p significantly decreased MIB1-luciferase activity in WT-MIB1 cells but had no impact on mut-MIB1 (Fig. 9E).

LncZFAS1 also regulates the activity of other miRs[41]. To determine whether LncZFAS1 upregulates MIB 1 through interference with miR590-3p, the transcriptional levels of miR590-3p were quantified in oeLncZFAS 1 cells. The results showed that oe-LncZFAS1 SH-SY5Ycells had significantly lower miR590-3p transcripts than the corresponding oe-vector control cells. In contrast, LncZFAS 1 knockdown significantly increased miR590-3p expression (Fig. 9F). Finally, to confirm that LncZFAS1 regulates miR590-3p pro-transcriptionally, the intracellular localization of LncZFAS1 was assessed by FISH staining and confocal microscopy. Consistent with the post-transcriptional regulation mechanism, LncZFAS1 expression was found to be mainly localized in the SHSY5Y cell cytoplasm following MPP ${ }^{+}$treatment (Fig. 9G). In contrast, sgRNA-ZFAS1 cells showed decreased MIB1 transcriptional and protein levels (Fig. 9I-K) and increased miR590-3p expression (Fig. 9L). 

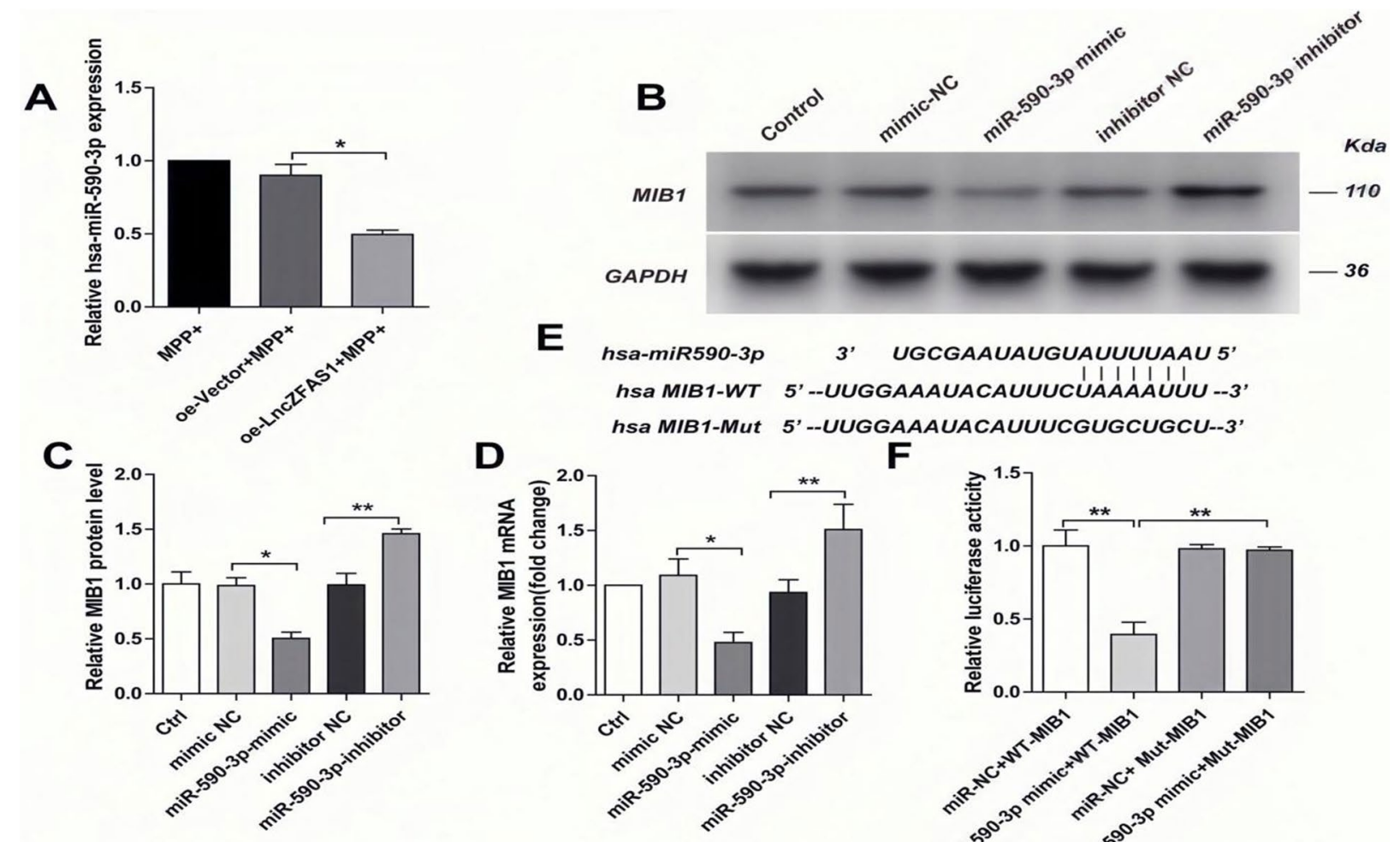

$\mathbf{G}$

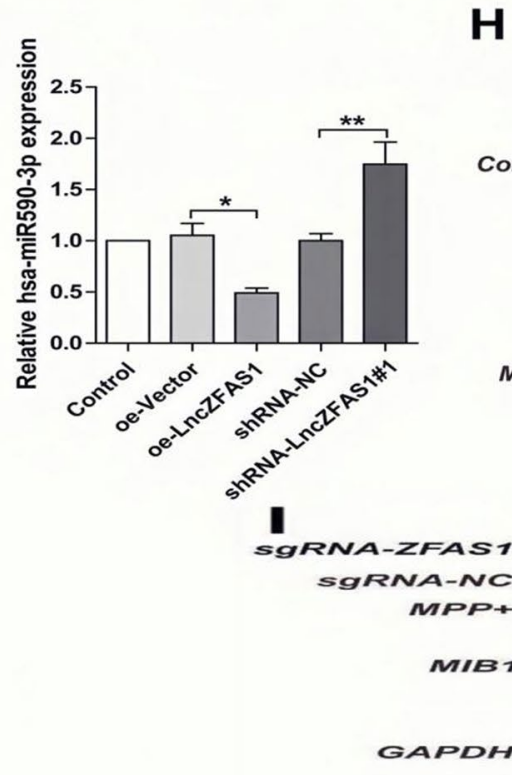

D

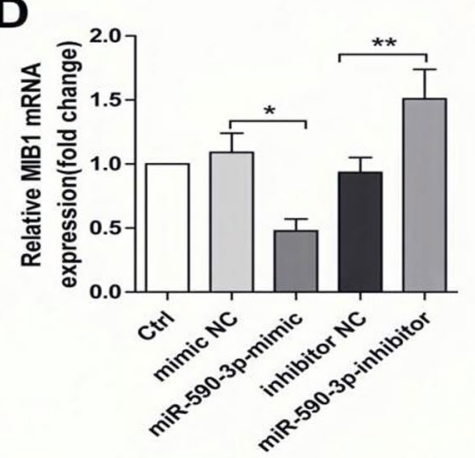

H

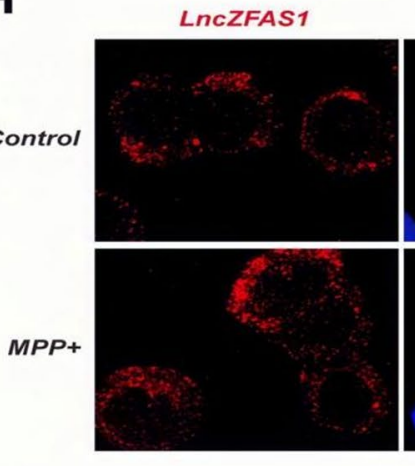

$\mathbf{F}$
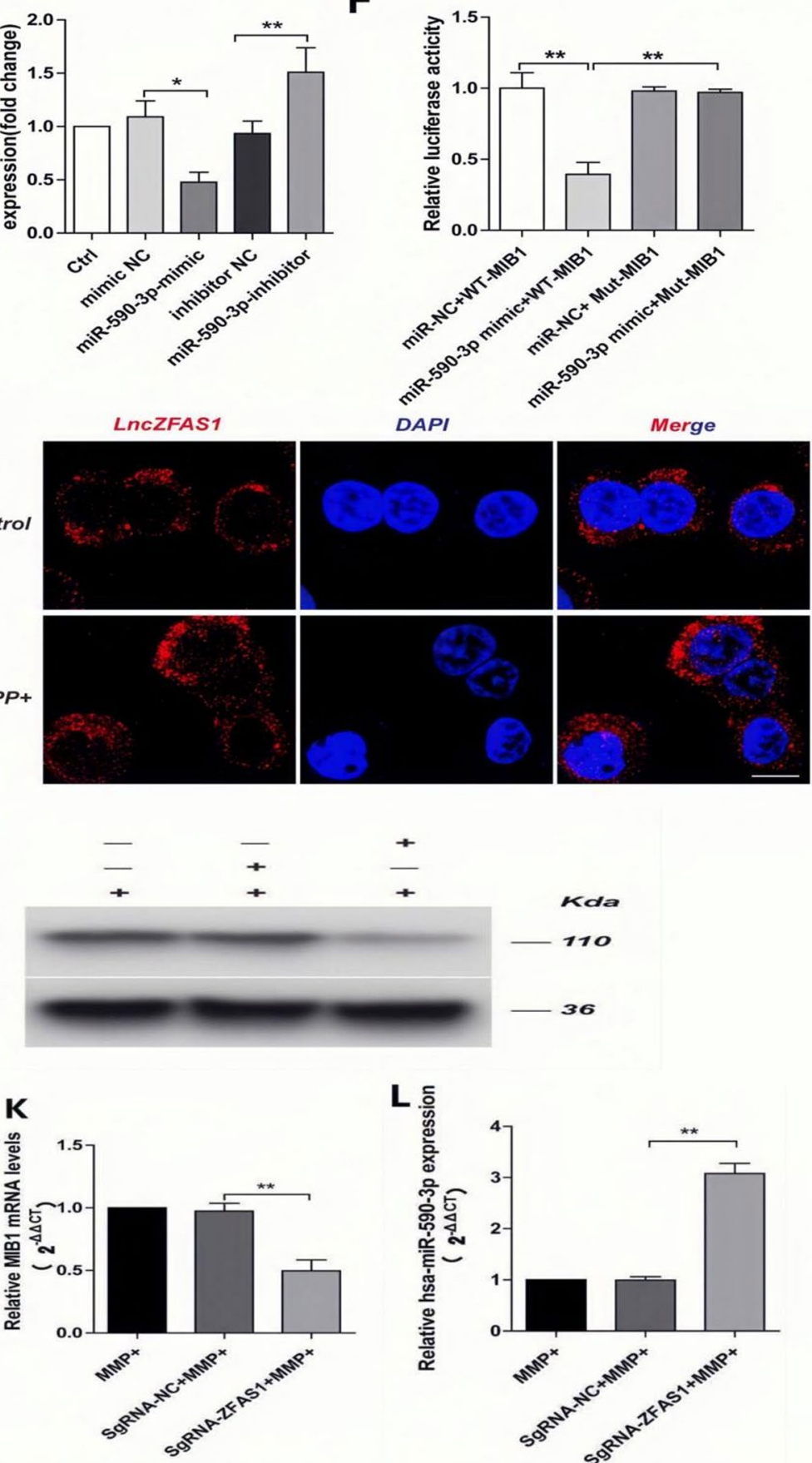

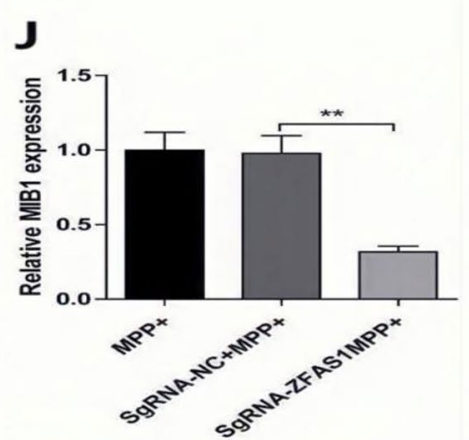


४Fig. 9 LncZFAS1 regulated miR590-3p-mediated MIB-1 inhibition. SH-SY5Y cells were stably transfected with lentiviral vector for LncZFAS1 overexpression or corresponding empty vector control, treated with $\mathrm{MPP}^{+}(1 \mathrm{mM})$ for $24 \mathrm{~h}$, and Mir590-3p transcriptional levels were measured by qRT-PCR (A). Sh-SY5Y cells were treated with miR590-3p mimic, miR590-inhibitor, or corresponding controls, and MIB1 levels measured by western blot $(\mathbf{B}, \mathbf{C})$ or qRT-PCR (D). A MIB1 luciferase reporter system was generated and the miR-590-3p 3'UTR target sequence mutated for resistance (E). Transfected cells were treated with miR590-3p mimic, miR590-inhibitor, or corresponding controls and MIB1 levels measured by luciferase activity (F). SH-SY5Y cells were stably transfected with lentiviral vector for LncZFAS1 overexpression, ShRNA-ZFAS1 for LcnZFAS1 knockdown, or corresponding controls, and miR509-3p levels measured by qRT-PCR (G). SH-SY5Y cells were treated with $\mathrm{MPP}^{+}(1 \mathrm{mM})$ for $24 \mathrm{~h}$ and LncZFAS1 intracellular localization determined by FISH staining and confocal microscopy. LncZFAS1 stably knockout SHSY5Y cells (sgRNA-ZFAS1) were treated with $\mathrm{MPP}^{+}(1 \mathrm{mM})$ for 24 $\mathrm{h}$ and MIB1 expression detected by western blot assay (I, J). MIB1 (K) and has-miR-590-3p (L) transcriptional levels were measured by qPCR. A, B, and $\mathbf{H}$ results were representative of three independent experiments. $\mathbf{C}, \mathbf{D}, \mathbf{F}, \mathbf{G}, \mathbf{J}, \mathbf{K}$, and $\mathbf{L}$ data represented as mean $\pm \mathrm{SD}$ of three individual experiments for each condition, performed in triplicate. $* p<0.05, * * p<0.01$

\section{Discussion}

Exploration of the non-coding genome unveiled a panoply of formerly unknown IncRNAs with critical regulatory functions in the pathophysiology of many neurological diseases[42-48]. LncRNAs are mainly expressed during cellular senescence, which represents a major risk factor during neurodegenerative disease development[46, 49]. Moreover, recent literature has shown that lncRNAs have important roles in regulating the expression of nearby protein-coding genes, and that deregulation of this relationship may lead to brain diseases. Most lncRNAs expressed in the nervous system have only been identified in genome-wide expression screens, but their involvement in Parkinson's disease is now a prolific research field[50-53]. This study showed that LncZFAS1 significantly regulated $\mathrm{MPP}^{+}$-induced pyroptosis and inflammasome activation in human neuroblasts. To our knowledge, this is the first report of a lncRNA directly regulating inflammasome activity in human neuroblasts, exposing lncZFAS as novel potential therapeutic approach for Parkinson's disease (Fig. 10).

Clinical and experimental research suggests that microglial activation and neuroinflammation are key regulators of dopaminergic neuronal loss in Parkinson's disease [54, 55]. Chronic activation of microglia and an excessive proinflammatory milieu in the brain can result in the expression of costimulatory molecules, neuroinflammation, and neuronal dysfunction[56-59]. Microglial-mediated neuroinflammation has been reported in many neurodegenerative disorders, and uncontrolled NLRP3 inflammasome activation in microglial cells has been observed in the tissue of the substantia nigra in the midbrain of patients with Parkinson's disease[56, 60]. Besides, NLRP3 inflammasome activation may aggravate dopaminergic neuronal loss in Parkinson's disease[24]. Both in vitro and in vivo models of Parkinson's disease have suggested a link between the aggregation of $\alpha$-synuclein, increased mitochondrial ROS, and cathepsin B release with the activation of microglial NLRP3 inflammation-mediated pyroptotic cell death of dopaminergic neurons in the substantia nigra[61-63]. In contrast, rare mutations in the NLRP3 inflammasome have been associated with a decreased risk of Parkinson's disease[64]. Furthermore, several etiological factors associated with neuroinflammation and dopaminergic neuronal loss, such as mitochondrial generation of ROS, mitophagy, loss of function of dopaminergic receptors, and IncRNA, are frequently connected with microglial NLRP3 inflammasome activation[63, 64]. Effectors of pyroptosis are activated and transferred to the membrane to induce glial rupture, releasing more inflammatory mediators, which promote the progression of Parkinson's disease with NLRP3[24]. Thus, the NLRP3 pathway may provide a new therapeutic avenue for Parkinson's disease treatment. However, the exact mechanism underlying NLRP3 activation in neural cells remains unclear, and a deeper understanding is necessary before this pathway can be targeted efficiently. Here, $\mathrm{MPP}^{+}$treatment significantly induced NLRP3 activation and pyroptosis in neuroblasts. Moreover, NLPR3 activation, ASC recruitment, caspase-1 cleavage, and IL- $1 \beta$ maturation were found to depend on the TXNIP/TRX1 interaction.

The thioredoxin (Trx) system (composed of NADPH, thioredoxin reductase, and Trx) is a key antioxidant system that protects cells from oxidative stress. Trx 1 is a $12-\mathrm{kDa}$ ubiquitous protein with disulfide-reducing activity, which is mainly localized in the cytoplasm[65]. TXNIP acts as an endogenous Trx inhibitor[66], and together, the Trx-Txnip complex has been recently described as novel protein signaling pathway for transducing redox-related signals[65]. TXNIP has a specific arrestin-like domain, which is responsible for highly promiscuous protein-protein interactions. Until now, TXNIP has been identified in association with importin- $\alpha$, transcriptional co-repressors SMRT-mSin3HDAC (histone deacetylase), Jab1, E3 ubiquitin ligase ITCH, Mybbp1a, and NLRP3, as well as Trx [37, 67-70]. Additionally, TXNIP-associated NLRP3 inflammasome activation plays an important role in degenerative and ischemic diseases such as Alzheimer's disease, Parkinson's disease, and stroke[71-73]. It has been observed that the expression of TXNIP was increased and knockdown of TXNIP by siRNA attenuated the NLRP3 inflammasome activation response in $\alpha$ Synagg-stimulated mouse microglial cells[73]. 


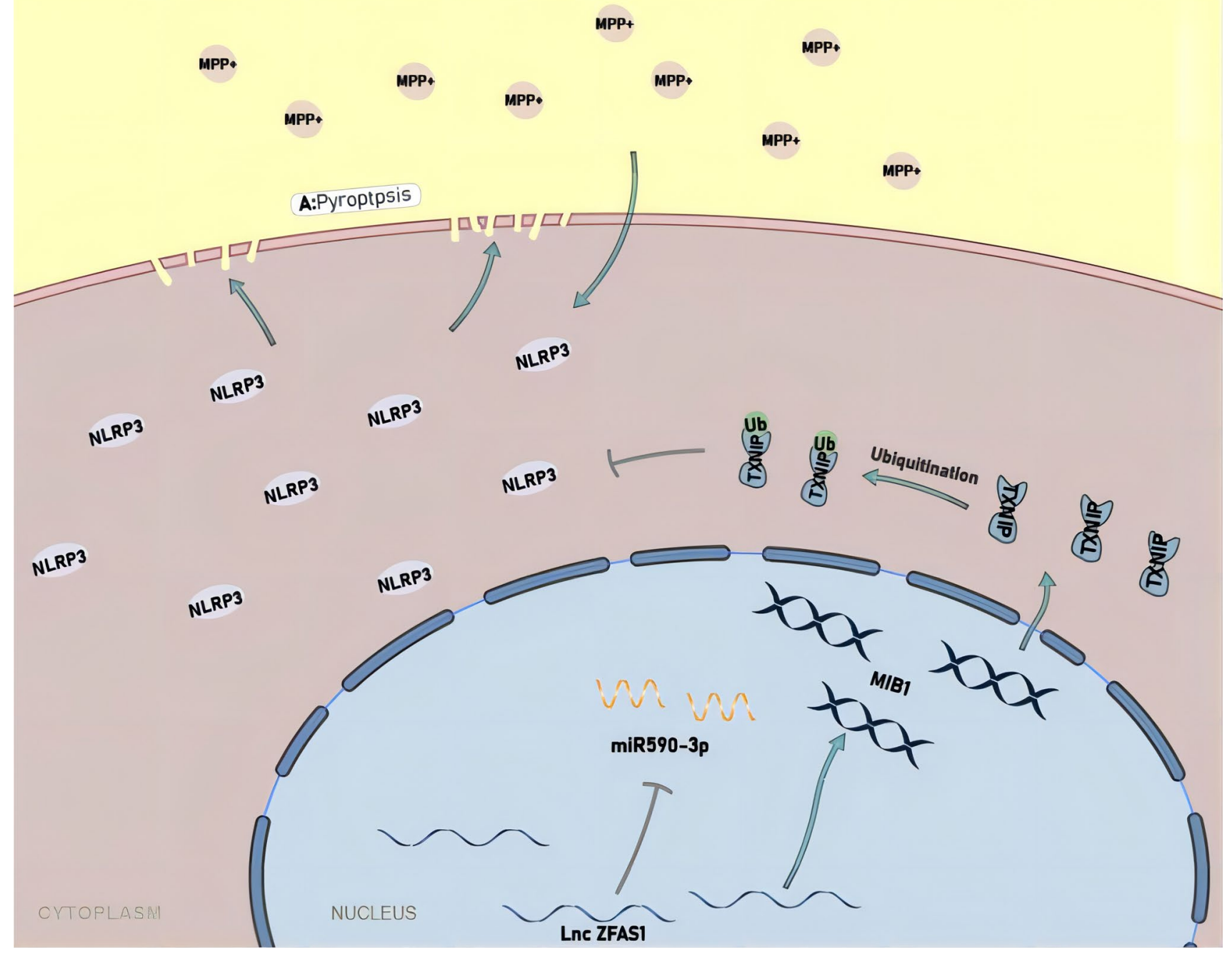

Fig. 10 Molecular mechanism for LncZFAS1 mediated inflammasome regulation in neuronal cells. Under homeostasis MIB1-mediated TXNIP ubiquitination inhibited inflammasome activation to maintain a tolerogenic environment. Upon a neuroinflammatory signal $\left(\mathrm{MPP}^{+}\right)$ miR590-3p upregulation inhibits MIB1 ubiquitin ligase, decreasing cytoplasmic Ub-TXNIP. In parallel, increased intracellular ROS acti-

Together, these findings revealed a central role of TXNIP in a redox signaling complex that results in inflammasome activation. In agreement with this hypothesis, decreased TXNIP expression in neuroblasts significantly decreased $\mathrm{MPP}^{+}$ inflammasome activation. A TXNIP centered inflammasome regulation mechanism has not yet been reported. Here, we showed that increased TXNIP ubiquitination, through MIB1 E3 ubiquitin ligase, regulates NLRP3 inflammasome activation in neuroblasts. Mechanistically, $\mathrm{MPP}^{+}$activated the NLPR3 inflammasome through miR590-3p upregulation, which in turn inhibited MIB1-dependent TXNIP ubiquitination. The increase in intracellular ROS then activated the TXNIP/TRX redox-sensing complex driving NLRP3/ASC association, caspase 1 activation, cytokine maturation, Grdm vated the Txnip/TRX redox-sensing complex driving NLRP3/ASC association, leading to NLRP3 inflammasome activation and break of tolerance. IncZFAS upregulation inhibited this entire pathway through direct interference with miR590-3p, preventing MIB1 ubiquitin ligase inhibition

cleavage, and pyroptosis. In contrast, lncZFAS could inhibit this entire pathway through direct interference with miR590$3 p$, exposing it as a new research avenue in exploring the mechanism of inflammasome activation and pyroptosis in neuroblasts and Parkinson's disease.

In this study, the Parkinson's disease-associated neuroinflammatory response was investigated using MPTPinduced cells $\left(\mathrm{MPP}^{+} \mathrm{SH}-\mathrm{SY} 5 \mathrm{Y}\right.$ cells), which, compared to microglia, are rarely used in this field. The results showed that MPTP-induced NLRP3 inflammasome activation in microglia played a central role in dopaminergic neurodegeneration and Parkinson's disease[17, 74]. NLRP3 promoted the secretion of IL- $1 \beta / 18$ and pyroptosis to rupture microglia to further release inflammatory factors in Parkinson's 
disease $[24,75,76]$. The changes in NLRP3 were observed in the MPTP-induced SH-SY5Y cell lines. Krishna et al. found that context-specific network integrity ranked ROS metabolism as the most intact, followed by the ubiquitin proteasome system, dopamine metabolism, calcium signaling, mitochondria, and glycolysis in different Parkinson's disease-related sub-systems of undifferentiated SH-SY5Y cells[77]. Thus, somatic mutations did not significantly alter Parkinson's disease-related pathways in the undifferentiated SH-SY5Y cells. Furthermore, $\mathrm{MPP}^{+}$inhibits complex I of the electron transport chain, increasing reactive ROS production, and redistributing DA to the cytosol to oxidize DA and generate more ROS[78]. Thus, SH-SY5Y cells are an appropriate model to study the effects of Parkinson's disease-related mitochondrial inhibition on cell viability and function[79, 80]. Mitochondrial reaction and ROS metabolism are important steps in the chain of the neuroinflammatory response. Therefore, MPTP-induced SH-SY5Y may be used as an alternative to study the Parkinson's disease neuroinflammatory response, which will extend the application of SH-SY5Y cell lines.

This study has several limitations. First, the characterization of the SH-SY5Y cell line showed moderate activity of dopamine- $\beta$-hydroxylase and negligible levels of choline acetyl-transferase and acetylcholinesterase, and butyrylcholinesterase, basal noradrenaline release, and tyrosine hydroxylase activity. Therefore, the SH-SY5Y cell line may display a catecholaminergic and not purely dopaminergic phenotype[79]. Second, the SH-SY5Y cell line was obtained as a neuroblastoma derivative, with cancerous properties that may have influenced the differentiation fate, viability, growth performance, metabolic properties, and genomic stability. Hence, SH-SY5Y cells possess physiological characteristics that differ greatly from the normal dopaminergic neuronal features[79]. Finally, although most of the genes belonging to the major Parkinson's disease pathways and modules were intact in the undifferentiated SH-SY5Y genome[78], it was unclear how the genes and modules were expressed in the $\mathrm{MPP}^{+} \mathrm{SH}-\mathrm{SY} 5 \mathrm{Y}$ cell line and what the differences in gene expression were between human Parkinson's disease and the $\mathrm{MPP}^{+} \mathrm{SH}-\mathrm{SY} 5 Y$ cell line. Thus, the MPP ${ }^{+}$model was not completely representative of neuroinflammation and pyroptosis pathology in human Parkinson's disease; however, this model still represents a direction worth exploring to maximize the benefit from SH-SY5Y cell line. Parkinson's disease-related neuroinflammation or pyroptosis should be explored in further studies using primary dopaminergic neuron-like cells differentiated from patient-derived induced pluripotent stem cells, other cellular neurotoxin models, genetic models, microglia, and animal models, including mouse, rat, and fruit fly.

In conclusion, IncZFAS overexpression inhibited the TXNIP/MIB1 E3 ubiquitin ligase/NLRP3 pathway through direct interference with miR590-3p, which shows a novel research avenue in exploring the mechanism of inflammasome activation and pyroptosis in Parkinson's disease.

Supplementary Information The online version contains supplementary material available at https://doi.org/10.1007/s12035-021-02619-z.

Acknowledgements The authors wish to acknowledge Better Papers Faster, and in particular Dr. Rodrigo B. Abreu, for assistance with scientific writing, editing, and consulting services.

Author Contribution $\mathrm{ZZ}$ and $\mathrm{PH}$ were responsible for the RNA and protein detection and co-immunoprecipitation (Co-IP) experiments. RS performed cell culture and lentiviral transfection experiments. XL was responsible for the pyroptosis and luciferase reporter experiments. WL performed the fluorescence in situ hybridization (FISH) and confocal microscopy analysis. WG was responsible for the conception and design of the work.

Funding This work was supported by the Natural Science Foundation of China (81972148), the Beijing Municipal Science and Technology Commission Capital Clinical Feature Applied Research Project (Z181100001718205), and the National Key Research and Development Program of China (2018YFC0115400).

Data Availability Not applicable.

Code Availability Not applicable.

\section{Declarations}

Consent to Participate Not applicable.

Consent for Publication All authors whose names appear on the submission agreed to the version to be published.

Competing Interests The authors declare no competing interests.

Open Access This article is licensed under a Creative Commons Attribution 4.0 International License, which permits use, sharing, adaptation, distribution and reproduction in any medium or format, as long as you give appropriate credit to the original author(s) and the source, provide a link to the Creative Commons licence, and indicate if changes were made. The images or other third party material in this article are included in the article's Creative Commons licence, unless indicated otherwise in a credit line to the material. If material is not included in the article's Creative Commons licence and your intended use is not permitted by statutory regulation or exceeds the permitted use, you will need to obtain permission directly from the copyright holder. To view a copy of this licence, visit http://creativecommons.org/licenses/by/4.0/.

\section{References}

1. de Rijk MC, Launer LJ, Berger K, Breteler MM, Dartigues JF, Baldereschi M, Fratiglioni L, Lobo A, Martinez-Lage J, Trenkwalder C, Hofman A (2000) Prevalence of Parkinson's disease in Europe: a collaborative study of population-based cohorts. Neurologic Diseases in the Elderly Research Group. Neurology (11 Suppl 5):S21-S23 
2. Dorsey ER, Constantinescu R, Thompson JP, Biglan KM, Holloway RG, Kieburtz K, Marshall FJ, Ravina BM, Schifitto G, Siderowf A, Tanner CM (2007) Projected number of people with Parkinson disease in the most populous nations, 2005 through 2030. Neurology (5):384-386. https://doi.org/10.1212/01.wnl. 0000247740.47667 .03

3. Zhang XM, Yin M, Zhang MH (2014) Cell-based assays for Parkinson's disease using differentiated human LUHMES cells. Acta Pharmacol Sin (7):945-956. https://doi.org/10.1038/aps.2014.36

4. Arnot CJ, Gay NJ, Gangloff M (2010) Molecular mechanism that induces activation of Spatzle, the ligand for the Drosophila Toll receptor. J Biol Chem (25):19502-19509. https://doi.org/10.1074/ jbc.M109.098186

5. Schmidt F, Champy P, Seon-Meniel B, Franck X, Raisman-Vozari R, Figadere B (2009) Chemicals possessing a neurotrophin-like activity on dopaminergic neurons in primary culture. Plos One (7):e6215. https://doi.org/10.1371/journal.pone.0006215

6. Son JH, Chun HS, Joh TH, Cho S, Conti B, Lee JW (1999) Neuroprotection and neuronal differentiation studies using substantia nigra dopaminergic cells derived from transgenic mouse embryos. J Neurosci (1): 10-20

7. Langston JW, Langston EB, Irwin I (1984) MPTP-induced parkinsonism in human and non-human primates - clinical and experimental aspects. Acta Neurol Scand Suppl:49-54

8. Gerhard A, Pavese N, Hotton G, Turkheimer F, Es M, Hammers A, Eggert K, Oertel W, Banati RB, Brooks DJ (2006) In vivo imaging of microglial activation with [11C](R)-PK11195 PET in idiopathic Parkinson's disease. Neurobiol Dis (2):404-412. https:// doi.org/10.1016/j.nbd.2005.08.002

9. He Y, Appel S, Le W (2001) Minocycline inhibits microglial activation and protects nigral cells after 6-hydroxydopamine injection into mouse striatum. Brain Res (1-2):187-193. https://doi.org/10. 1016/s0006-8993(01)02681-6

10. Wu DC, Jackson-Lewis V, Vila M, Tieu K, Teismann P, Vadseth C, Choi DK, Ischiropoulos H, Przedborski S (2002) Blockade of microglial activation is neuroprotective in the 1-methyl-4-phenyl1,2,3,6-tetrahydropyridine mouse model of Parkinson disease. J Neurosci (5):1763-1771

11. Edison P, Ahmed I, Fan Z, Hinz R, Gelosa G, Ray CK, Walker Z, Turkheimer FE, Brooks DJ (2013) Microglia, amyloid, and glucose metabolism in Parkinson's disease with and without dementia. Neuropsychopharmacol (6):938-949. https://doi.org/10.1038/ npp. 2012.255

12. Schroder K, Tschopp J (2010) The inflammasomes. Cell (6):821832. https://doi.org/10.1016/j.cell.2010.01.040

13. Rathinam VA, Fitzgerald KA (2016) Inflammasome complexes: emerging mechanisms and effector functions. Cell (4):792-800. https://doi.org/10.1016/j.cell.2016.03.046

14. Jo EK, Kim JK, Shin DM, Sasakawa C (2016) Molecular mechanisms regulating NLRP3 inflammasome activation. Cell Mol Immunol (2):148-159. https://doi.org/10.1038/cmi.2015.95

15. Guo H, Callaway JB, Ting JP (2015) Inflammasomes: mechanism of action, role in disease, and therapeutics. Nat Med (7):677-687. https://doi.org/10.1038/nm.3893

16. Ozaki E, Campbell M, Doyle SL (2015) Targeting the NLRP3 inflammasome in chronic inflammatory diseases: Current perspectives. J Inflamm Res:15-27. https://doi.org/10.2147/JIR.S51250

17. Lee E, Hwang I, Park S, Hong S, Hwang B, Cho Y, Son J, Yu JW (2019) MPTP-driven NLRP3 inflammasome activation in microglia plays a central role in dopaminergic neurodegeneration. Cell Death Differ (2):213-228. https://doi.org/10.1038/ s41418-018-0124-5

18. Shao BZ, Xu ZQ, Han BZ, Su DF, Liu C (2015) NLRP3 inflammasome and its inhibitors: a review. Front Pharmacol:262. https:// doi.org/10.3389/fphar.2015.00262
19. Broz P, Dixit VM (2016) Inflammasomes: mechanism of assembly, regulation and signalling. Nat Rev Immunol (7):407-420. https://doi.org/10.1038/nri.2016.58

20. Gurung P, Lukens JR, Kanneganti TD (2015) Mitochondria: diversity in the regulation of the NLRP3 inflammasome. Trends Mol Med (3):193-201. https://doi.org/10.1016/j.molmed.2014.11.008

21. Heid ME, Keyel PA, Kamga C, Shiva S, Watkins SC, Salter RD (2013) Mitochondrial reactive oxygen species induces NLRP3dependent lysosomal damage and inflammasome activation. J Immunol (10):5230-5238. https://doi.org/10.4049/jimmunol. 1301490

22. Sorbara MT, Girardin SE (2011) Mitochondrial ROS fuel the inflammasome. Cell Res (4):558-560. https://doi.org/10.1038/cr. 2011.20

23. Vanaja SK, Rathinam VA, Fitzgerald KA (2015) Mechanisms of inflammasome activation: recent advances and novel insights. Trends Cell Biol (5):308-315. https://doi.org/10.1016/j.tcb.2014. 12.009

24. Wang S, Yuan YH, Chen NH, Wang HB (2019) The mechanisms of NLRP3 inflammasome/pyroptosis activation and their role in Parkinson's disease. Int Immunopharmacol:458-464. https://doi. org/10.1016/j.intimp.2018.12.019

25. Yao RW, Wang Y, Chen LL (2019) Cellular functions of long noncoding RNAs. Nat Cell Biol (5):542-551. https://doi.org/10. 1038/s41556-019-0311-8

26. Poliseno L, Salmena L, Zhang J, Carver B, Haveman WJ, Pandolfi PP (2010) A coding-independent function of gene and pseudogene mRNAs regulates tumour biology. Nature (7301):1033-1038. https://doi.org/10.1038/nature09144

27. Salmena L, Poliseno L, Tay Y, Kats L, Pandolfi PP (2011) A ceRNA hypothesis: the Rosetta Stone of a hidden RNA language? Cell (3):353-358. https://doi.org/10.1016/j.cell.2011.07.014

28. Elkouris M, Kouroupi G, Vourvoukelis A, Papagiannakis N, Kaltezioti V, Matsas R, Stefanis L, Xilouri M, Politis PK (2019) Long non-coding RNAs associated with neurodegenerationlinked genes are reduced in Parkinson's disease patients. Front Cell Neurosci:58. https://doi.org/10.3389/fncel.2019.00058

29. Hadjicharalambous MR, Roux BT, Feghali-Bostwick CA, Murray LA, Clarke DL, Lindsay MA (2018) Long non-coding RNAs are central regulators of the IL-1beta-induced inflammatory response in normal and idiopathic pulmonary lung fibroblasts. Front Immunol:2906. https://doi.org/10.3389/fimmu.2018. 02906

30. Askarian-Amiri ME, Crawford J, French JD, Smart CE, Smith MA, Clark MB, Ru K, Mercer TR, Thompson ER, Lakhani SR, Vargas AC, Campbell IG, Brown MA, Dinger ME, Mattick JS (2011) SNORD-host RNA Zfas1 is a regulator of mammary development and a potential marker for breast cancer. Rna (5):878-891. https://doi.org/10.1261/rna.2528811

31. Zhang Y, Sun L, Xuan L, Pan Z, Li K, Liu S, Huang Y, Zhao X, Huang L, Wang Z, Hou Y, Li J, Tian Y, Yu J, Han H, Liu Y, Gao F, Zhang Y, Wang S, Du Z, Lu Y, Yang B (2016) Reciprocal changes of circulating long non-coding RNAs ZFAS1 and CDR1AS predict acute myocardial infarction. Sci Rep:22384. https://doi.org/10.1038/srep22384

32. Wu T, Wu D, Wu Q, Zou B, Huang X, Cheng X, Wu Y, Hong K, Li P, Yang R, Li Y, Cheng Y (2017) Knockdown of long non-coding rna-ZFAS1 protects cardiomyocytes against acute myocardial infarction via anti-apoptosis by regulating miR-150/CRP. J Cell Biochem (10):3281-3289. https://doi.org/10.1002/jcb.25979

33. Ye Y, Gao X, Yang N (2018) LncRNA ZFAS1 promotes cell migration and invasion of fibroblast-like synoviocytes by suppression of miR-27a in rheumatoid arthritis. Hum Cell (1):14-21. https://doi.org/10.1007/s13577-017-0179-5

34. Dong D, Mu Z, Wang W, Xin N, Song X, Shao Y, Zhao C (2017) Prognostic value of long noncoding RNA ZFAS1 in various 
carcinomas: a meta-analysis. Oncotarget (48):84497-84505. https://doi.org/10.18632/oncotarget.21100

35. Makkar R, Behl T, Bungau S, Kumar A, Arora S (2020) Understanding the role of inflammasomes in rheumatoid arthritis. Inflammation (6):2033-2047. https://doi.org/10.1007/ s10753-020-01301-1

36. He A, He S, Li X, Zhou L (2019) ZFAS1: a novel vital oncogenic lncRNA in multiple human cancers. Cell Prolif (1):e12513. https://doi.org/10.1111/cpr.12513

37. Zhou R, Tardivel A, Thorens B, Choi I, Tschopp J (2010) Thioredoxin-interacting protein links oxidative stress to inflammasome activation. Nat Immunol (2):136-140. https://doi.org/10.1038/ni. 1831

38. Filhoulaud G, Benhamed F, Pagesy P, Bonner C, Fardini Y, Ilias A, Movassat J, Burnol AF, Guilmeau S, Kerr-Conte J, Pattou F, Issad T, Postic C (2019) O-GlcNacylation links TxNIP to inflammasome activation in pancreatic beta cells. Front Endocrinol (Lausanne):291. https://doi.org/10.3389/fendo.2019.00291

39. Lopez-Castejon G (2020) Control of the inflammasome by the ubiquitin system. Febs J (1):11-26. https://doi.org/10.1111/febs. 15118

40. Wang H, Cai J (2017) The role of microRNAs in heart failure. Biochim Biophys Acta Mol Basis Dis (8):2019-2030. https://doi. org/10.1016/j.bbadis.2016.11.034

41. Dong D, Mu Z, Zhao C, Sun M (2018) ZFAS1: a novel tumorrelated long non-coding RNA. Cancer Cell Int:125. https://https:// doi.org/10.1186/s12935-018-0623-y

42. Akula N, Barb J, Jiang X, Wendland JR, Choi KH, Sen SK, Hou L, Chen DT, Laje G, Johnson K, Lipska BK, Kleinman JE, CorradaBravo H, Detera-Wadleigh S, Munson PJ, Mcmahon FJ (2014) RNA-sequencing of the brain transcriptome implicates dysregulation of neuroplasticity, circadian rhythms and GTPase binding in bipolar disorder. Mol Psychiatry (11):1179-1185. https://doi.org/ 10.1038/mp.2013.170

43. Barry $\mathrm{G}$ (2014) Integrating the roles of long and small non-coding RNA in brain function and disease. Mol Psychiatry (4):410-416. https://doi.org/10.1038/mp.2013.196

44. Johnson R, Richter N, Jauch R, Gaughwin PM, Zuccato C, Cattaneo E, Stanton LW (2010) Human accelerated region 1 noncoding RNA is repressed by REST in Huntington's disease. Physiol Genomics (3):269-274. https://doi.org/10.1152/physiolgenomics. 00019.2010

45. Ng SY, Lin L, Soh BS, Stanton LW (2013) Long noncoding RNAs in development and disease of the central nervous system. Trends Genet (8):461-468. https://doi.org/10.1016/j.tig.2013.03.002

46. Sarkar SN, Russell AE, Engler-Chiurazzi EB, Porter KN, Simpkins JW (2019) MicroRNAs and the genetic nexus of brain aging, neuroinflammation, neurodegeneration, and brain trauma. Aging Dis(2):329-352. https://doi.org/10.14336/AD.2018.0409

47. Wang S, Zhang X, Guo Y, Rong H, Liu T (2017) The long noncoding RNA HOTAIR promotes Parkinson's disease by upregulating LRRK2 expression. Oncotarget (15):24449-24456. https://doi. org/10.18632/oncotarget.15511

48. Faghihi MA, Modarresi F, Khalil AM, Wood DE, Sahagan BG, Morgan TE, Finch CE, St LGR, Kenny PJ, Wahlestedt C (2008) Expression of a noncoding RNA is elevated in Alzheimer's disease and drives rapid feed-forward regulation of beta-secretase. Nat Med (7):723-730. https://doi.org/10.1038/nm1784

49. Chakrabarti S, Mohanakumar KP (2016) Aging and neurodegeneration: a tangle of models and mechanisms. Aging Dis (2):111113. https://doi.org/10.14336/AD.2016.0312

50. Marki S, Goblos A, Szlavicz E, Torok N, Balicza P, Bereznai B, Takats A, Engelhardt J, Klivenyi P, Vecsei L, Molnar MJ, Nagy N, Szell M (2018) The rs13388259 intergenic polymorphism in the genomic context of the BCYRN1 gene is associated with
Parkinson's disease in the Hungarian population. Parkinsons Dis:9351598. https://doi.org/10.1155/2018/9351598

51. Ni Y, Huang H, Chen Y, Cao M, Zhou H, Zhang Y (2017) Investigation of long non-coding RNA expression profiles in the substantia nigra of Parkinson's disease. Cell Mol Neurobiol (2):329-338. https://doi.org/10.1007/s10571-016-0373-0

52. Saracchi E, Fermi S, Brighina L (2014) Emerging candidate biomarkers for Parkinson's disease: a review. Aging Dis (1):27-34 https://doi.org/10.14366/AD.2014.050027

53. Soreq L, Guffanti A, Salomonis N, Simchovitz A, Israel Z, Bergman H, Soreq H (2014) Long non-coding RNA and alternative splicing modulations in Parkinson's leukocytes identified by RNA sequencing. Plos Comput Biol (3):e1003517. https://doi.org/10. 1371/journal.pcbi.1003517

54. Jellinger KA (2012) Neuropathology of sporadic Parkinson's disease: evaluation and changes of concepts. Mov Disord (1):8-30. https://doi.org/10.1002/mds.23795

55. Rocha NP, de Miranda AS, Teixeira AL (2015) Insights into neuroinflammation in Parkinson's disease: from biomarkers to AntiInflammatory based therapies. Biomed Res Int:628192. https:// doi.org/10.1155/2015/628192

56. Gordon R, Albornoz EA, Christie DC, Langley MR, Kumar V, Mantovani S, Robertson A, Butler MS, Rowe DB, O'Neill LA, Kanthasamy AG, Schroder K, Cooper MA, Woodruff TM (2018) Inflammasome inhibition prevents alpha-synuclein pathology and dopaminergic neurodegeneration in mice. Sci Transl Med (465). https://doi.org/10.1126/scitranslmed.aah4066

57. Kinney JW, Bemiller SM, Murtishaw AS, Leisgang AM, Salazar AM, Lamb BT (2018) Inflammation as a central mechanism in Alzheimer's disease. Alzheimers Dement (N Y):575-590. https:// doi.org/10.1016/j.trci.2018.06.014

58. Moss DW, Bates TE (2001) Activation of murine microglial cell lines by lipopolysaccharide and interferon-gamma causes NOmediated decreases in mitochondrial and cellular function. Eur J Neurosci(3):529-538. https://doi.org/10.1046/j.1460-9568.2001. 01418.x

59. Nayak D, Roth TL, Mcgavern DB (2014) Microglia development and function. Annu Rev Immunol:367-402. https://doi.org/10. 1146/annurev-immunol-032713-120240

60. Javed H, Thangavel R, Selvakumar GP, Dubova I, Schwartz N, Ahmed ME, Zaheer S, Kempuraj D, Iyer S, Zaheer A, Khan MM (2020) NLRP3 inflammasome and glia maturation factor coordinately regulate neuroinflammation and neuronal loss in MPTP mouse model of Parkinson's disease. Int Immunopharmacol:106441. https://doi.org/10.1016/j.intimp.2020.106441

61. Beraud D, Twomey M, Bloom B, Mittereder A, Ton V, Neitzke K, Chasovskikh S, Mhyre TR, Maguire-Zeiss KA (2011) AlphaSynuclein alters Toll-Like receptor expression. Front Neurosci:80. https://doi.org/10.3389/fnins.2011.00080

62. Codolo G, Plotegher N, Pozzobon T, Brucale M, Tessari I, Bubacco L, de Bernard M (2013) Triggering of inflammasome by aggregated alpha-synuclein, an inflammatory response in synucleinopathies. Plos One (1):e55375. https://doi.org/10.1371/journ al.pone.0055375

63. Sarkar S, Malovic E, Harishchandra DS, Ghaisas S, Panicker N, Charli A, Palanisamy BN, Rokad D, Jin H, Anantharam V, Kanthasamy A, Kanthasamy AG (2017) Mitochondrial impairment in microglia amplifies NLRP3 inflammasome proinflammatory signaling in cell culture and animal models of Parkinson's disease. NPJ Parkinsons Dis:30. https://doi.org/10.1038/ s41531-017-0032-2

64. von Herrmann KM, Salas LA, Martinez EM, Young AL, Howard JM, Feldman MS, Christensen BC, Wilkins OM, Lee SL, Hickey WF, Havrda MC (2018) NLRP3 expression in mesencephalic neurons and characterization of a rare NLRP3 polymorphism 
associated with decreased risk of Parkinson's disease. NPJ Parkinsons Dis:24. https://doi.org/10.1038/s41531-018-0061-5

65. Yoshihara E, Masaki S, Matsuo Y, Chen Z, Tian H, Yodoi J (2014) Thioredoxin/Txnip: redoxisome, as a redox switch for the pathogenesis of diseases. Front Immunol:514. https://doi.org/10.3389/ fimmu.2013.00514

66. Nishiyama A, Matsui M, Iwata S, Hirota K, Masutani H, Nakamura H, Takagi Y, Sono H, Gon Y, Yodoi J (1999) Identification of thioredoxin-binding protein-2/vitamin $\mathrm{D}(3)$ up-regulated protein 1 as a negative regulator of thioredoxin function and expression. J Biol Chem (31):21645-21650. https://doi.org/10.1074/jbc. 274.31.21645

67. Ago T, Liu T, Zhai P, Chen W, Li H, Molkentin JD, Vatner SF, Sadoshima J (2008) A redox-dependent pathway for regulating class II HDACs and cardiac hypertrophy. Cell (6):978-993. https:// doi.org/10.1016/j.cell.2008.04.041

68. Jeon JH, Lee KN, Hwang CY, Kwon KS, You KH, Choi I (2005) Tumor suppressor VDUP1 increases p27(kip1) stability by inhibiting JAB1. Cancer Res(11):4485-4489. https://https://doi.org/10. 1158/0008-5472.CAN-04-2271

69. Yamaguchi F, Takata M, Kamitori K, Nonaka M, Dong Y, Sui L, Tokuda M (2008) Rare sugar D-allose induces specific upregulation of TXNIP and subsequent G1 cell cycle arrest in hepatocellular carcinoma cells by stabilization of p27kip1. Int J Oncol (2):377-385

70. Yoshihara E, Fujimoto S, Inagaki N, Okawa K, Masaki S, Yodoi J, Masutani H (2010) Disruption of TBP-2 ameliorates insulin sensitivity and secretion without affecting obesity. Nat Commun:127. https://doi.org/10.1038/ncomms1127

71. Li L, Ismael S, Nasoohi S, Sakata K, Liao FF, Mcdonald MP, Ishrat T (2019) Thioredoxin-interacting protein (TXNIP) associated NLRP3 inflammasome activation in human Alzheimer's disease brain. J Alzheimers Dis (1):255-265. https://doi.org/10. 3233/JAD-180814

72. Ismael S, Nasoohi S, Yoo A, Ahmed HA, Ishrat T (2020) Tissue plasminogen activator promotes TXNIP-NLRP3 inflammasome activation after hyperglycemic stroke in mice. Mol Neurobiol(6):2495-2508. https://doi.org/10.1007/s12035-020-01893-7

73. Samidurai M, Palanisamy BN, Bargues-Carot A, Hepker M, Kondru N, Manne S, Zenitsky G, Jin H, Anantharam V, Kanthasamy AG, Kanthasamy A (2021) PKC delta activation promotes endoplasmic reticulum stress (ERS) and NLR family pyrin Domain-Containing 3 (NLRP3) inflammasome activation subsequent to a synuclein-induced microglial activation: involvement of thioredoxin-interacting protein (TXNIP)/thioredoxin (Trx) redoxisome pathway. Front Aging Neurosci:661505. https://doi. org/10.3389/fnagi.2021.661505

74. Qin Y, Qiu J, Wang P, Liu J, Zhao Y, Jiang F, Lou H (2021) Impaired autophagy in microglia aggravates dopaminergic neurodegeneration by regulating NLRP3 inflammasome activation in experimental models of Parkinson's disease. Brain Behav Immun:324-338. https://doi.org/10.1016/j.bbi.2020.10.010

75. Gao MR, Wang M, Jia YY, Tian DD, Liu A, Wang WJ, Yang L, Chen JY, Yang Q, Liu R, Wu YM (2020) Echinacoside protects dopaminergic neurons by inhibiting NLRP3/caspase-1/IL-1beta signaling pathway in MPTP-induced Parkinson's disease model. Brain Res Bull:55-64. https://doi.org/10.1016/j.brainresbull.2020. 08.015

76. Zhang Q, Huang XM, Liao JX, Dong YK, Zhu JL, He CC, Huang J, Tang YW, Wu D, Tian JY (2020) LncRNA HOTAIR promotes neuronal damage through facilitating NLRP3 Mediated-Pyroptosis activation in Parkinson's disease via regulation of miR-326/ ELAVL1 axis. Cell Mol Neurobiol. https://doi.org/10.1007/ s10571-020-00946-8

77. Krishna A, Biryukov M, Trefois C, Antony PM, Hussong R, Lin J, Heinaniemi M, Glusman G, Koglsberger S, Boyd O, van den Berg BH, Linke D, Huang D, Wang K, Hood L, Tholey A, Schneider R, Galas DJ, Balling R, May P (2014) Systems genomics evaluation of the SH-SY5Y neuroblastoma cell line as a model for Parkinson's disease. Bmc Genomics:1154. https://doi.org/10. 1186/1471-2164-15-1154

78. Jagmag SA, Tripathi N, Shukla SD, Maiti S, Khurana S (2015) Evaluation of models of Parkinson's disease. Front Neurosci:503. https://doi.org/10.3389/fnins.2015.00503

79. Xicoy H, Wieringa B, Martens GJ (2017) The SH-SY5Y cell line in Parkinson's disease research: a systematic review. Mol Neurodegener(1):10. https://doi.org/10.1186/s13024-017-0149-0

80. Korecka JA, van Kesteren RE, Blaas E, Spitzer SO, Kamstra JH, Smit AB, Swaab DF, Verhaagen J, Bossers K (2013) Phenotypic characterization of retinoic acid differentiated SH-SY5Y cells by transcriptional profiling. Plos One(5):e63862. https://doi.org/10. 1371/journal.pone.0063862

Publisher's Note Springer Nature remains neutral with regard to jurisdictional claims in published maps and institutional affiliations. 